University of Wollongong

Research Online

Faculty of Engineering and Information

Faculty of Engineering and Information

Sciences - Papers: Part A

Sciences

$1-1-2014$

\title{
Simplified mapping rule for bounding surface simulation of complex loading paths in granular materials
}

Mojtaba E. Kan

University of New South Wales, mojtaba@uow.edu.au

Hossein Taiebat

University of New South Wales, h.taiebat@unsw.edu.au

Nasser Khalili

University of New South Wales, n.khalil@unsw.edu.au

Follow this and additional works at: https://ro.uow.edu.au/eispapers

Part of the Engineering Commons, and the Science and Technology Studies Commons

Research Online is the open access institutional repository for the University of Wollongong. For further information contact the UOW Library: research-pubs@uow.edu.au 


\title{
Simplified mapping rule for bounding surface simulation of complex loading paths in granular materials
}

\author{
Abstract \\ This paper presents a bounding surface plasticity model that can be used to simulate complex monotonic \\ and cyclic loading paths.A new mapping rule that only uses the last stress reversal point is introduced to \\ describe the stress-strain behavior of granular soils during loading and unloading. This mapping rule is \\ easy to implement and is suitable for highly erratic cyclic loading conditions, e.g., those induced by earth- \\ quake or traffic loading. The application and performance of the model are demonstrated using the \\ results of experimental tests with various stress paths conducted under both monotonic and cyclic \\ loading conditions. The study shows the efficiency of the new mapping rule in cap- turing the \\ characteristic features of the behavior of granular soils under various loading paths.

\section{Disciplines} \\ Engineering | Science and Technology Studies

\section{Publication Details} \\ Kan, M. E., Taiebat, H. A. \& Khalili, N. (2014). Simplified mapping rule for bounding surface simulation of \\ complex loading paths in granular materials. International Journal of Geomechanics, 14 (2), 239-253.
}




\title{
1 A Simplified Mapping Rule for Bounding Surface Simulation of Complex Loading Paths in Granular Materials
}

\author{
Mojtaba E. Kan ${ }^{1}$; Hossein A. Taiebat ${ }^{2}$ and Nasser Khalili ${ }^{3}$
}

Abstract: This paper presents a bounding surface plasticity model that can be used to

6 simulate complex monotonic and cyclic loading paths. A new mapping rule which only uses

7 the last stress reversal point is introduced to describe the stress-strain behaviour of granular

8 soils during loading and unloading. This mapping rule is easy to implement and is suitable for

9 highly erratic cyclic loading condition, e.g. those induced by earthquake or traffic loading.

10 The application and performance of the model is demonstrated using the results of

11 experimental tests with various stress paths conducted under both monotonic and cyclic loading conditions. The study shows the efficiency of the new mapping rule in capturing the characteristic features of the behaviour of granular soils under various loading paths.

Keywords: bounding surface plasticity; mapping rule; cyclic loading; granular soil

\footnotetext{
${ }^{1}$ Research scholar, School of Civil and Environmental Engineering, The University of New South Wales, Sydney, NSW 2052, Australia. Email: m.esfahanikan@unsw.edu.au

${ }^{2}$ Senior Lecturer, School of Civil and Environmental Engineering, The University of New South Wales, Sydney, NSW 2052, Australia. Email: h.taiebat@unsw.edu.au

${ }^{3}$ Professor, School of Civil and Environmental Engineering, The University of New South Wales, Sydney, NSW 2052, Australia. Email: n.khalil@unsw.edu.au
} 
The concept of bounding surface plasticity was first introduced by Dafalias and Popov (1975) and Krieg (1975) to model nonlinear behaviour of materials under complex loading. In this approach, the plastic deformation at a stress point is calculated by defining the plastic modulus as a decreasing function of the distance of the stress point from its "image point" on a limiting surface called the bounding surface. This provides a smooth transition of stiffness from elastic to elastic-plastic state. By using a three-segmented bounding surface with a simple radial projection rule and a distance dependent additive plastic modulus, Dafalias and Hermann (1980) applied the theory of bounding surface plasticity to cohesive soils. Later, Bardet (1986) extended the application of the bounding surface models to nonlinear irreversible behaviour of sands, including strain softening and stress dilatancy observed in dense sands. This was achieved by defining the plastic modulus as a function of the mean effective stress and the stress ratio. However, the model proposed was based on the associativity of flow rule, and was unable to capture the post-peak strain-softening behaviour of loose sands under undrained shearing. Further developments of the bounding surface model were due to Crouch (1994) for 2D cases and Crouch and Wolf (1994a\&b) for 3D cases, in which the combined radial and deviatoric mapping rules, non-associate flow rule, the bi-linear critical state line and the apparent normal consolidation line for sands were included. The shortcomings of this model were the complex shape of bounding surface, lack of continuity between the two mapping regions used in the model and the large number of model parameters.

More recently, a more rigorous bounding surface model based on the concept of the critical state soil mechanics was developed at The University of New South Wales (UNSW) by Russell and Khalili (2004) to model the stress-strain behaviour of sands. Later Khalili et al. (2005 \& 2008) extended the model to simulate the behaviour of sands subjected to cyclic 
loading under saturated and unsaturated states including hydraulic hysteresis effects. In this model, hereafter referred to as UNSW constitutive model, the shape of the bounding surface was obtained from experimental observations of undrained stress path responses of soils at their loosest state. A mapping rule, passing through stress reversal points, was introduced to predict the stress-strain behaviour under loading and unloading. Compared with the classical bounding surface models, UNSW model was able to capture well the characteristic features of granular soils subjected to cyclic loading (e.g. the contraction during deviatoric unloading), as well as the behaviour of normally and over consolidated clayey materials. However, the mapping rule adopted, despite its excellent performance in capturing the cyclic behavior of soils, could not be applied efficiently to highly variable loading paths due to its complex procedure and the storage and memory requirement in a boundary value problem. To tackle this problem, a single stress point mapping rule is introduced in this study which has a simpler procedure and is more amenable to application to complex loading paths. The performance of the new mapping rule is illustrated by comparing the results of simulation of the model using the two mapping rules. The new mapping rule is then employed to simulate the behaviour of different soils under various monotonic and cyclic loading paths.

The novel aspects of the current work are threefold:

- The model formulation is extended to three-dimensional stress space (i.e. $p^{\prime}-q-\theta$ ).

- A new mapping rule is introduced which has less complexity and brings more robustness and efficiency in numerical modelling of highly complex cyclic loading paths; e.g. earthquake loading.

- A host of new simulations, for a variety of different stress paths, including conventional drained and undrained triaxial tests, constant mean effective stress tests, constant confining stress tests, anisotropically consolidated and anisotropic compression tests are presented to highlight the capabilities of the model. A single set 

data are taken from different references in the literature.

\section{PRELIMINARIES}

\section{$71 \quad$ Notation}

72 Soil mechanics sign is adopted throughout. Compression is taken as positive and tension as negative. For the sake of simplicity, all derivations are presented in the $p^{\prime}-q$ plane in a

74 three-dimensional stress space such that

$$
p^{\prime}=-\frac{I^{\prime}}{3}, q=\sqrt{3 J_{2}}
$$

76 where $I^{\prime}=\boldsymbol{\sigma}^{T} \boldsymbol{\delta}$ is the first invariant of the effective stress tensor, $J_{2}=\frac{1}{2}\left(\mathbf{s}^{T} \mathbf{s}\right)$ is the second

77 invariant of the deviator stress tensor, $\mathbf{s}=\boldsymbol{\sigma}-\frac{1}{3}\left(\boldsymbol{\sigma}^{T} \boldsymbol{\delta}\right) \boldsymbol{\delta}$, and $\delta$ is Kronecker delta. The 78 corresponding strain conjugates are

$$
\varepsilon_{v}=-\widehat{I}, \varepsilon_{q}=\frac{2}{\sqrt{3}} \sqrt{\widehat{J}_{2}}
$$

80 where $\widehat{I}=\varepsilon^{T} \boldsymbol{\delta}$ and $\widehat{J}_{2}=\frac{1}{2}\left(\widehat{\mathbf{s}}^{T} \widehat{\mathbf{s}}\right)$ are the first and the second invariants of the strain vector,

81 respectively, and $\widehat{\mathbf{s}}=\boldsymbol{\varepsilon}-\frac{1}{3}\left(\boldsymbol{\varepsilon}^{T} \boldsymbol{\delta}\right) \boldsymbol{\delta}$.

82 The total strain increments are divided into elastic and plastic components as

$$
\dot{\varepsilon}=\dot{\varepsilon}^{e}+\dot{\varepsilon}^{p}
$$


84

where the superscripts $e$ and $p$ denote the elastic and plastic components, respectively. The volumetric strain, $\varepsilon_{v}$, is related to the specific volume $(v)$ as

$$
\varepsilon_{v}=\ln \left(\frac{v}{v_{0}}\right)
$$

where $v_{0}=1+e_{0}$ is the specific volume at the reference mean effective stress, $v=1+e$, and $e$ and $e_{0}$ are the current void ratio and the void ratio at the reference point, respectively. The material behaviour is assumed isotropic and rate independent.

\section{Critical State}

The critical state is the ultimate condition towards which all states approach with increasing deviatoric shear strain. Figure 1 shows the Critical State Line (CSL) in the $v-\ln p^{\prime}$ plane, approximated by two linear segments (after Been et al., 1991). More specifically, four parameters are used to define the critical state line (CSL) in the $v-\ln p^{\prime}$ plane: $\lambda_{0}$ and $\Gamma_{0}$ are the slope of the initial portion of the CSL and its specific volume at $p^{\prime}=1 \mathrm{kPa}$, respectively; $p_{c r}^{\prime}$ is the mean effective stress at the onset of particle crushing; and $\lambda_{c r}$ is the slope of CSL during the particle crushing stage. A dimensionless state parameter $(\xi)$ is defined as a measure of consistency of the soil under its current state; it is positive on the loose side of CSL and negative on the dense side, and is defined as

$$
\xi=v-v_{c s}
$$

where $v$ is the specific volume at the current stress, $p^{\prime}$, and $v_{c s}$ is the specific volume at the critical state corresponding to $p^{\prime}$. 
103 The CSL in the $q-p^{\prime}$ plane is defined as a straight line passing through the origin. Following

104 Sheng et al. (2000), the slope of the CSL, $M_{c s}$, is defined as a function of Lode angle, $\theta$,

$$
M_{c s}(\theta)=M_{\max }\left(\frac{2 \alpha^{4}}{1+\alpha^{4}-\left(1-\alpha^{4}\right) \sin 3 \theta}\right)^{\frac{1}{4}}
$$

106 where $\theta$ is defined as $\theta=\frac{1}{3} \sin ^{-1}\left(-\frac{3 \sqrt{3}}{2} \frac{J_{3}}{\sqrt{\left(J_{2}\right)^{3}}}\right), J_{2}$ and $J_{3}$ are the second and third

107 invariants of stress vector. Lode angle ranges from $\theta=-\frac{\pi}{6}$ for triaxial extension to $\theta=+\frac{\pi}{6}$

108 for triaxial compression. Here, $\alpha$ is a function of the strength parameter of soil and can be 109 given as

$$
\alpha=\frac{3-\sin \varphi_{c s}^{\prime}}{3+\sin \varphi_{c s}^{\prime}}
$$

111 where $\phi_{c s}^{\prime}$ is the critical state internal frictional angle and is considered independent of 112 crushing of particles. $M_{\max }$ is the value of $M_{c s}$ for triaxial compression which is linked to the 113 critical state friction angle and can be given as

$$
M_{\max }=\frac{6 \sin \phi_{c s}^{\prime}}{3-\sin \phi_{c s}^{\prime}}
$$

115 The proposed shape of the failure surface coincides with the Mohr-Coulomb failure surface at 116 all vertices in the deviatoric plane. It is also noted that $\alpha=1$ recovers the von Mises failure 117 surface.

118 The Limiting Isotropic Compression Line (LICL) is defined as parallel to the CSL with a constant shift in $v-\ln p^{\prime}$ plane along the recompression line, as shown in Figure 1, Similar to

120 the critical state line, the LICL is a reference line in the $q-p^{\prime}$ space, which can be viewed as 
121 locus of the loosest possible state for a soil under a given mean effective stress. Given the

122 expression of CSL as

123

$$
v=f\left(p^{\prime}\right)
$$

124 the LICL is expressed as

$$
v=f\left(\bar{p}^{\prime}\right)=f\left(p^{\prime}\right)-\kappa \ln R
$$

126 where $\bar{p}^{\prime}=R \cdot p^{\prime}$, and $R$ is a model parameter.

\section{STRESS STRAIN RELATIONSHIP}

128 The incremental elastic strains are linked to the incremental stresses through

$$
\dot{\boldsymbol{\sigma}}^{\prime}=\mathbf{D}^{e} \dot{\boldsymbol{\varepsilon}}^{e}
$$

130 where $\mathbf{D}^{e}$ is the elastic property matrix which can be defined as a function of the bulk

131 modulus, $\mathrm{K}$, and the shear modulus, $\mathrm{G}$.

132 The incremental plastic strain-stress relationship is written as

$$
\dot{\boldsymbol{\varepsilon}}^{p}=\frac{1}{h} \mathbf{m n}^{T} \dot{\boldsymbol{\sigma}}^{\prime}
$$

134 where $\mathbf{n}$ is the unit vector normal to the loading surface at the current stress state, $\boldsymbol{\sigma}^{\prime}, \mathbf{m}$ is

135 the unit direction of plastic flow at $\boldsymbol{\sigma}^{\prime}$, and $h$ is the hardening modulus. Substituting (12) and

136 (3) in (11) the elastic-plastic stress-strain relationship is obtained as

$$
\dot{\boldsymbol{\sigma}}^{\prime}=\left(\mathbf{D}^{e}-\frac{\mathbf{D}^{e} \mathbf{m} \mathbf{n}^{T} \mathbf{D}^{e}}{h+\mathbf{n}^{T} \mathbf{D}^{e} \mathbf{m}}\right) \dot{\boldsymbol{\varepsilon}}
$$


138 The bulk and shear elastic moduli are calculated assuming that unloading/reloading occurs

139 along a $\kappa$ line in the $v-\ln p^{\prime}$ plane. The moduli are then defined as

$$
\begin{gathered}
K=\frac{v p^{\prime}}{\kappa} \\
G=\frac{3(1-2 v)}{2(1+v)} \frac{v p^{\prime}}{\kappa}
\end{gathered}
$$

where $v$ is the Poisson's ratio.

\section{ELASTO-PLASTIC BEHAVIOUR}

144 The essential elements of a bounding surface plasticity model are: (i) a bounding surface for

145 describing the limit states of stress; (ii) a loading surface on which the current stress state lies

146 and a mapping rule to find the image point on the bounding surface; (iii) a plastic potential for

147 describing the mode and magnitudes of plastic deformations, and (iv) a hardening rule for

148 controlling the size of the bounding surface and the location of the loading surfaces.

149 Following the work of Khalili et al. (2005), the domain of purely elastic response is assumed

150 to be nil and all deformation is considered elastic-plastic. This is achieved by defining the

151 hardening modulus, $h$, as a decreasing function of the distance between the stress state, $\boldsymbol{\sigma}^{\prime}$, and

152 an "image point", $\overline{\boldsymbol{\sigma}}^{\prime}$ on the bounding surface. During loading the size of the loading surface

153 increases so that any unloading/reloading results in elastic-plastic deformation. Detailed

154 definitions of the bounding surface, the loading surface and mapping rule, the plastic potential,

155 and the hardening rule are given in the following sections. The stress conditions on the

156 bounding surface are denoted using a superimposed bar throughout this notes. 


\section{Bounding Surface}

158 Accurate descriptions of the bounding surface are required in order to avoid complications in

159 the stress-strain simulations of soil, particularly under undrained conditions. The shape of the

160 bounding surface is best selected experimentally. It can be determined from the undrained

161 response of the material at its loosest state. It should be mentioned that the undrained response

162 of the material in the effective stress space follows the bounding surface when the

163 contribution of elasticity to volume change is negligible. Examining a host of experimental

164 data, Russell and Khalili (2004) and Khalili et al. (2005) suggested the following expression

165 for the shape of the bounding surface:

166

$$
F\left(\bar{p}^{\prime}, \bar{q}, \bar{\theta}, \bar{p}_{c}^{\prime}\right)=\left(\frac{\bar{q}}{M_{c s}(\bar{\theta}) \bar{p}^{\prime}}\right)^{N}-\frac{\ln \left(\bar{p}_{c}^{\prime} / \bar{p}^{\prime}\right)}{\ln R}=0
$$

167 The parameter $\bar{p}_{c}^{\prime}$ controls the size of the bounding surface and is a function of the plastic

168 volumetric strain. The material constant $R$ represents the ratio of $\bar{p}_{c}^{\prime}$ and the mean effective

169 stress at the intercept of the bounding surface with the CSL in the $q-p^{\prime}$ space. The constant

$170 N$ controls the curvature of the bounding surface. The effects of different magnitudes of $N$

171 and $R$ on the three-dimensional shape of the bounding surface are illustrated in Figure 2.

\section{Loading Surface and Mapping Rule}

173 The loading surface is assumed to be of the same shape as the bounding surface. For first time

174 loading these two surfaces are homologous about the origin of the stress coordinate system. In

175 this case, the function for the loading surface takes the form of

176

$$
F\left(p^{\prime}, q, \theta, p_{c}^{\prime}\right)=\left(\frac{q}{M_{c s}(\theta) p^{\prime}}\right)^{N}-\frac{\ln \left(p_{c}^{\prime} / p^{\prime}\right)}{\ln R}=0
$$


where $p_{c}^{\prime}$ is the isotropic hardening parameter controlling the size of the loading surface as

178 illustrated in Figure 3. The state of stress, $\boldsymbol{\sigma}^{\prime}$, is always located on the loading surface. An 179 image for the state of stress can be found on the bounding surface, $\overline{\boldsymbol{\sigma}}^{\prime}$, as shown in Figure 3.

180 The centre of homology, $\boldsymbol{\sigma}^{\prime}$ and $\overline{\boldsymbol{\sigma}}^{\prime}$ are used to define the mapping rule. For unloading and 181 reloading conditions, the centre of homology moves to the last point of stress reversal. The 182 point of stress reversal is identified when the product of the normal vector to the bounding 183 surface $(\mathbf{n})$ and the vector of the stress increment $\left(\dot{\boldsymbol{\sigma}}_{e}^{\prime}\right)$ becomes negative (Pastor et al, 1990), 184 where $\dot{\boldsymbol{\sigma}}_{e}^{\prime}$ is calculated using the total strain as $\mathbf{D}^{e} \times \dot{\boldsymbol{\varepsilon}}$. The image of the stress point in the $185 p^{\prime}-q$ plane is located using the Pegasus method (Dowell and Jarratt, 1972 and Sloan et al., 186 2001). Upon stress reversal, a new loading surface is formed with the new centre of 187 homology, as shown in Figure 4a. To maintain similarity with the bounding surface, the 188 loading surfaces undergo kinematic hardening during loading and unloading. This mapping 189 rule is simpler and easier to be implemented as compared to the one used originally by Khalili et al. (2005).

191 In order to locate the image point for unloading/reloading condition, Khalili et al. (2005)

192 introduced the maximum loading surface at the point of stress reversal as the local bounding 193 surface and formed a new loading surface at the centre of homology. The image point was 194 then located sequentially by projecting the stress point onto a series of intermediate image 195 points on successive local bounding surfaces each passing through a point of stress reversal 196 (Figure 4b). The loading history of the soil was captured through the stress reversal points and 197 the corresponding maximum loading surfaces. Application of such a complex mapping rule is 198 not efficient in simulation of a boundary value problem with highly erratic cyclic loading 199 paths, such as those that occur under earthquake loading conditions. The history of stress reversal points and the geometry of intermediate local bounding surfaces should also be 
tracked during unloading/reloading conditions, which increases the memory requirement in a

202 large boundary value problem.

203 The new single stress point mapping rule, proposed in this study, locates the image point 204 directly on the bounding surface, as shown in Figure 4a, without forming successive 205 intermediate local bounding surfaces. This version of the mapping rule is easier to be 206 implemented, does not require the history of previous loading surfaces, and is more suitable 207 for simulation of high frequency cyclic loading, e.g. due to earthquake, vibration, traffic 208 loading and blasting and real life applications where previous stress history of the soil is 209 unknown.

210 The unit normal vector at the image point defining the direction of loading is given using the 211 general equation:

$$
\mathbf{n}=\frac{\partial F / \partial \overline{\boldsymbol{\sigma}}^{\prime}}{\left\|\partial F / \partial \overline{\boldsymbol{\sigma}}^{\prime}\right\|}
$$

213 The vector $\partial F / \partial \overline{\boldsymbol{\sigma}}^{\prime}$ is evaluated applying the chain rule of differentiation:

$$
\frac{\partial F}{\partial \bar{\sigma}^{\prime}}=\frac{\partial F}{\partial \bar{p}^{\prime}} \frac{\partial \bar{p}^{\prime}}{\partial \bar{\sigma}^{\prime}}+\frac{\partial F}{\partial \bar{q}^{\prime}} \frac{\partial \bar{q}^{\prime}}{\partial \bar{\sigma}^{\prime}}+\frac{\partial F}{\partial \bar{\theta}^{\prime}} \frac{\partial \bar{\theta}^{\prime}}{\partial \bar{\sigma}^{\prime}}
$$

215 Recalling the generalized definitions of the invariants $\bar{p}^{\prime}, \bar{q}$ and $\bar{\theta}$, their derivatives with 216 respect to $\overline{\boldsymbol{\sigma}}^{\prime}$ become

$$
\frac{\partial \bar{p}^{\prime}}{\partial \overline{\boldsymbol{\sigma}}^{\prime}}=-\frac{1}{3} \boldsymbol{\delta}
$$

$$
\frac{\partial \bar{q}^{\prime}}{\partial \overline{\boldsymbol{\sigma}}^{\prime}}=\frac{3}{2 \bar{q}}\left(\overline{\boldsymbol{\sigma}}^{\prime}-\boldsymbol{\delta} \frac{\bar{I}}{3}\right)
$$




$$
\frac{\partial \bar{\theta}}{\partial \overline{\mathbf{\sigma}}^{\prime}}=-\frac{\sqrt{3}}{2 \sqrt{\bar{J}_{2}^{3}} \cos 3 \bar{\theta}}\left(\frac{\partial \bar{J}_{3}}{\partial \overline{\boldsymbol{\sigma}}^{\prime}}-\frac{3 \bar{J}_{3}}{2 \bar{J}_{2}} \frac{\partial \bar{J}_{2}}{\partial \overline{\mathbf{\sigma}}^{\prime}}\right)
$$

220

221

\section{Plastic Potential}

$$
\frac{\partial F}{\partial \bar{q}}=\frac{N}{M_{c s}(\bar{\theta}) \bar{p}^{\prime}}\left(\frac{\bar{q}}{M_{c s}(\bar{\theta}) \bar{p}^{\prime}}\right)^{N-1}=\frac{N}{\bar{q}}\left(\frac{\bar{q}}{M_{c s}(\bar{\theta}) \bar{p}^{\prime}}\right)^{N}
$$

$$
\frac{\partial F}{\partial \bar{\theta}}=-\frac{3 N}{4}\left(\frac{\bar{q}}{M_{c s}(\bar{\theta}) \bar{p}^{\prime}}\right)^{N}\left(\frac{\left(1-\alpha^{4}\right) \cos 3 \bar{\theta}}{1+\alpha^{4}-\left(1-\alpha^{4}\right) \sin 3 \bar{\theta}}\right)
$$

The plastic potential defines the direction of plastic strain increments. Since plastic behaviour is characterized by the link between strain increments and stresses, the plastic potential is generally expressed using a plastic flow rule relating the plastic dilatancy $\left(d=\dot{\varepsilon}_{v}^{p} / \dot{\varepsilon}_{q}^{p}\right)$ to the stress ratio $q / p^{\prime}$. In this work, the plastic potential $(g)$ is defined as

$$
g\left(p^{\prime}, q, \bar{\theta}, p_{o}\right)=\tilde{t} q+\frac{A M_{c s}(\bar{\theta}) p^{\prime}}{A-1}\left(\left(\frac{p^{\prime}}{p_{o}}\right)^{A-1}-1\right) \quad \text { for } A \neq 1
$$

$$
g\left(p^{\prime}, q, \bar{\theta}, p_{o}\right)=\tilde{t} q+M_{c s}(\bar{\theta}) p^{\prime} \ln \left(\frac{p^{\prime}}{p_{o}}\right) \quad \text { for } A=1
$$


where $p_{0}$ controls the size of the plastic potential, though it is not required in the model since

233 only derivatives of the $(g)$ function are incorporated in formulations, and $A$ is a material 234 parameter. The direction of plastic flow is defined by:

$$
\mathbf{m}=\frac{\partial g / \partial \boldsymbol{\sigma}^{\prime}}{\left\|\partial g / \partial \boldsymbol{\sigma}^{\prime}\right\|}
$$

236 in which $\partial g / \partial \boldsymbol{\sigma}^{\prime}$ is evaluated applying the chain rule of differentiation:

$$
\frac{\partial g}{\partial \boldsymbol{\sigma}^{\prime}}=\frac{\partial g}{\partial p^{\prime}} \frac{\partial p^{\prime}}{\partial \boldsymbol{\sigma}^{\prime}}+\frac{\partial g}{\partial q} \frac{\partial q}{\partial \boldsymbol{\sigma}^{\prime}}+\frac{\partial g}{\partial \bar{\theta}} \frac{\partial \bar{\theta}}{\partial \boldsymbol{\sigma}^{\prime}}
$$

$238 \partial g / \partial p^{\prime}, \partial g / \partial q$ and $\partial g / \partial \theta$ are evaluated by differentiating the plastic potential with respect 239 to $p^{\prime}, q$ and $\bar{\theta}$.

$$
\frac{\partial g}{\partial p^{\prime}}=A\left(M_{c s}(\bar{\theta})-\tilde{t} \frac{q}{p^{\prime}}\right)
$$

$$
\frac{\partial g}{\partial q}=\tilde{t}
$$

$$
\frac{\partial g}{\partial \bar{\theta}}=-\tilde{t} \frac{3 q}{4}\left(\frac{\left(1-\alpha^{4}\right) \cos 3 \bar{\theta}}{1+\alpha^{4}-\left(1-\alpha^{4}\right) \sin 3 \bar{\theta}}\right)
$$

243 In the above equations $\tilde{t}$ is a scalar, the sign of which controls the direction of plastic flow in 244 the deviatoric plane. At any stress point two vectors of plastic flow are identified, one 245 corresponding to compressive loading $\left(\mathrm{m}^{+}\right)$and the other to extensive $\left(\mathrm{m}^{-}\right)$as shown in 246 Figure 5. The direction of plastic flow is controlled by $\tilde{t}$, which is determined based on the 247 relative positions of the stress point, $\boldsymbol{\sigma}^{\prime}$, and its image point, $\overline{\boldsymbol{\sigma}}^{\prime}$, by comparing the angle 
248 between a given reference axis and the stress point $\left(\gamma_{\sigma}\right)$ and the angle between the reference

249 axis and the image point $\left(\gamma_{\bar{\sigma}}\right)$ :

$$
\tilde{t}=+1 \quad \text { for }\left|\gamma_{\bar{\sigma}}-\gamma_{\sigma}\right|<\pi / 2
$$

$$
\tilde{t}=-1 \quad \text { for }\left|\gamma_{\bar{\sigma}}-\gamma_{\sigma}\right|>\pi / 2
$$

\section{Hardening Modulus}

253 In the bounding surface plasticity, the hardening modulus $h$ consist of two components

$$
h=h_{b}+h_{f}
$$

255 where $h_{b}$ is the plastic modulus at $\overline{\boldsymbol{\sigma}}^{\prime}$ on the bounding surface, and $h_{f}$ is plastic modulus at $256 \boldsymbol{\sigma}^{\prime}$ and defined as a function of the distance between $\boldsymbol{\sigma}^{\prime}$ and $\overline{\boldsymbol{\sigma}}^{\prime}$. Applying the consistency 257 condition at the bounding surface and assuming isotropic hardening of the bounding surface 258 with plastic volumetric compression, the derivative of the bounding surface can be obtained 259 as

260

$$
\dot{F}=\left(\frac{\partial F}{\partial \boldsymbol{\sigma}^{\prime}}\right)^{T} \dot{\boldsymbol{\sigma}}^{\prime}+\frac{\partial F}{\partial \bar{p}_{c}^{\prime}} \frac{\partial \bar{p}_{c}^{\prime}}{\partial \varepsilon_{v}^{p}} \dot{\varepsilon}_{v}^{p}
$$

261 Then, the flow rule will be

$$
\dot{\varepsilon}_{v}^{p}=\dot{\Lambda} \frac{\partial g}{\partial p^{\prime}}
$$

263 Using the definition of the unit vector normal to the bounding surface, equation (37) can be 264 rewritten as

$$
\dot{F}=\mathbf{n}^{T} \dot{\boldsymbol{\sigma}}^{\prime}-\dot{\Lambda} h_{b}=0
$$


in which $h_{b}$ is calculated as

267

$$
h_{b}=-\frac{\partial F}{\partial \bar{p}_{c}^{\prime}} \frac{\partial \bar{p}_{c}^{\prime}}{\partial \varepsilon_{v}^{p}} \frac{m_{p}}{\left\|\partial F / \partial \overline{\boldsymbol{\sigma}}^{\prime}\right\|}
$$

268 with $m_{p}=\frac{\partial g / \partial \bar{p}^{\prime}}{\left\|\partial g / \partial \boldsymbol{\sigma}^{\prime}\right\|}$. Differentiating equation (16) with respect to $\bar{p}_{c}^{\prime}$ yields to

$$
\frac{\partial F}{\partial \bar{p}_{c}^{\prime}}=\frac{-1}{\bar{p}_{c}^{\prime} \ln R}
$$

270 For isotropic hardening rule, the evolution of $\bar{p}_{c}^{\prime}$ with $\varepsilon_{v}^{p}$ is in turn given by

$$
\frac{\partial \bar{p}_{c}^{\prime}}{\partial \varepsilon_{v}^{p}}=\frac{v \bar{p}_{c}^{\prime}}{\lambda-\kappa}
$$

272 where $\lambda$ is the current slope of the LICL in the $v-\ln p^{\prime}$. Substituting equations (40) and (41)

273 into equation (39) yields

$$
h_{b}=\frac{v}{(\lambda-\kappa) \ln R} \frac{m_{p}}{\left\|\partial F / \partial \overline{\boldsymbol{\sigma}}^{\prime}\right\|}
$$

275 The modulus $h_{f}$ is defined such that it is zero on the bounding surface and infinity at the point 276 of stress reversal, and can take from of

$$
h_{f}=\frac{v p^{\prime}}{(\lambda-\kappa)}\left(\frac{\bar{p}_{c}^{\prime}}{p_{c}^{\prime}}-1\right) k_{m}\left(\eta_{p}-\tilde{t} \eta\right)
$$

278 where $\bar{p}_{c}^{\prime}$ and $p_{c}^{\prime}$ define the sizes of the bounding and loading surfaces, respectively, $\eta_{p}$ is 279 the slope of the peak strength line in the $q-p^{\prime}$ plane, and $k_{m}$ is a scaling parameter 280 controlling the steepness of the response in the $q-\varepsilon_{q}$ plane. The slope of the peak strength 
281 line is a function of the state parameter and the slope of the critical state line, which is given 282 as

$$
\eta_{p}=\tilde{t}(1-k \xi) M_{c s}
$$

where $k$ is a material parameter.

The scaling parameter $k_{m}$ can be taken as a material constant for some soils, though it is strongly influenced by the initial state parameters and the loading direction (Khalili et al., 2005). Russell and Khalili (2004\&2006), examined a wide range of triaxial tests on granular materials and concluded that $k_{m}$ can be expressed as a function of the initial value of the dimensionless state parameter, $\xi_{0}$ (equation 5) and initial confining pressure, $p_{0}^{\prime}$. In this study a general expression for $k_{m}$ is suggested as follows:

$$
k_{m}=k_{m 0}\left\langle 1.0-\beta_{1} \exp \left(\xi_{0}\right)\right\rangle\left(p_{0}^{\prime}\right)^{\beta_{2}}
$$

where $k_{m 0}, \beta_{1}$ and $\beta_{2}$ are material parameters.

\section{APPLICATION}

294 To demonstrate robustness and application of the model, a series of comparative simulations 295 is first performed using the new and the original mapping rules (Khalili et al., 2005). This is 296 followed by a host of non-standard monotonic and complex cyclic simulations.

\section{Performance of the New Mapping Rule}

298 To examine the effect of the mapping rule on the performance of the model, cyclic responses 299 of Hostun, Fuji River and Toyoura sands are investigated. 
The results of the drained cyclic test simulation on a dense sample of Hostun sand using the 301 original mapping rule (Khalili at al. (2005) and the simplified one are presented in Figure 6. 302 Also shown in this figure are the experimental data reported by Saada et al. (1989). The initial conditions of the sample were $p^{\prime}=350 \mathrm{kPa}$ and $v=1.61$ and the material parameters are selected as $\kappa=0.003, v=0.1, M_{c s}=1.31, \lambda_{0}=0.028, \lambda_{c r}=0.24, \Gamma_{0}=2.037, N=2.3$, $R=7.5, A=1.0$ and $k=2.0$ with $k_{m}=3.5$ for the first time loading and $k_{m}=35.0$ for unloading and reloading, similar to those used by Khalili et al. (2005).

Figure 6 shows that the performance of the new mapping rule is as good as that of the more complex original mapping rule when compared with the results of the experimental data. Both mapping rules capture the stiffening of the material response during unloading and reloading, simulate the contraction of the sample during unloading and the subsequent dilation during reloading. A better match with the experimental data could have been achieved if the model properties were calibrated for the new mapping rule however this was avoided for the sake of consistency of the comparisons.

Figure 7 shows the results of simulation of a cyclic drained test on loose Fuji River sand conducted by Tatsuoka and Ishihara (1974), where the variations of stress ratio versus deviatoric and volumetric strains are presented. In this test the amplitude of the cyclic loading

317 increases gradually at each cycle. The initial conditions of the sample were $p^{\prime}=196 \mathrm{kPa}$ and $v=1.74$. The basic material parameters are selected according to those used by Khalili et al. (2005), i.e., $\quad \kappa=0.01, v=0.3, M_{c s}=1.48, \lambda_{0}=0.032, \lambda_{c r}=0.21, \Gamma_{0}=1.870, N=3.0$, $R=6.2, A=1.0$ and $k=2.0$; with $k_{m}=0.13$ for the first time loading and $k_{m}=8.0$ for 321 unloading and reloading.

322 The results of the simulations show that both mapping rules capture the main features of the 323 behavior of the sand under cyclic loading. The predictions of the two mapping rules are very 
similar, except that the new mapping rule predicts a larger volumetric strain than the original mapping rule. However, when compared with the experimental data, the performance of the new mapping rule can be regarded to be as good as the original mapping rule. Figure 7 shows that simplifications of the original mapping rule do not affect the performance of the model, in particular, in simulation of the contractive responses during loading and unloading and the stiffening of the behaviour with successive cycles.

330 The effects of the two mapping rules on the response of the model are also shown in Figure 8, where the results of simulation for a drained cyclic test on Toyoura sand with constant mean effective stress (Pradhan et al. 1989b) are presented. The material parameters and state variables are taken to be the same in both simulations, i.e., $p^{\prime}=98.1 \mathrm{kPa}, v=1.845$ $\kappa=0.001, v=0.3, M_{c s}=1.24, \lambda_{0}=0.03, \lambda_{c r}=0.24, \Gamma_{0}=1.969, N=3.0, R=5.8$, $A=1.0, k=2.0$; with $k_{m}=1.0$ for the first time loading and $k_{m}=3.0$ for unloading and reloading. Once again both simulations result in very close match with the experimental data. Figure 8 shows noticeable differences in the volumetric strains predicted by the two mapping rules, especially under low cyclic load amplitudes; the volumetric strain is overestimated by

339 the original mapping rule and underestimated by the new mapping rule, when compared with 340 the experimental data. However, under higher cyclic amplitude the performance of the model 341 with the new mapping rule is superior to that with the original mapping rule.

342 A comparison of the results of the simulations of the model using the two mapping rules 343 indicates that the simplification of the original mapping rule does not affect the performance 344 of the model, especially when the results are compared with the experimental data. The new 345 mapping rule has the advantages of being robust and simpler than the original one and 346 therefore is recommended to be used for complex cyclic loading. 


\section{Further Validation}

348 To further examine the performance of the model with the new mapping rule a number of

349 well documented cases from literature are selected and analyzed, such as tests on Nevada sand 350 (Arulmoli et al., 1992) and Toyoura sand (Verdugo and Ishihara, 1996, and Pradhan et al., 351 1989a). The material parameters used for these simulations are listed in Table 1 and Table 2.

352 The procedure to obtain the material parameters are described by Russell and Khalili (2004) 353 and Khalili et al. (2005).

\section{Drained and Undrained Tests on Nevada Sand}

Nevada sand was used in VELACS project (Arulmoli et al., 1992) under both 1g laboratory conditions and in centrifuge experiments. The triaxial experiments reported in that project are used here for calibration purpose as well as for verification of the performance of the model. Kutter et al. (1994) and Chen (1995) have also reported the results of a series of triaxial and torsional shear tests on Nevada sand which are used in this study for definition of the material properties. Samples of the triaxial tests in VELACS project were $63.5 \mathrm{~mm}$ in diameter and prepared using dry pluviation method. The samples were subjected to a variety of nonstandard drained and undrained monotonic stress paths, among them are those of triaxial compression tests shown in Figure 9. The triaxial experiments were performed on both loose $\left(D_{r}=40 \%\right)$ and dense $\left(D_{r}=60 \%\right)$ samples under different confining pressures. The material parameters are shown in Table 1and Table 2.

The results of the simulation of CIDC tests (Figure 9) on loose as well as dense samples of Nevada sand are presented in Figure 10 and Figure 11, respectively. These tests were conducted under drained conditions where the samples were loaded isotropically under 3 different confining pressures of $p_{0}^{\prime}=40,80,160 \mathrm{kPa}$, followed by loading under constant mean effective stresses. The model captures the experimentally observed initial hardening 
371 behaviour of loose sands accompanied by a volumetric contraction until the critical state is

372 reached (Figure 10). For the dense sand the experimental data do not show a clear softening

373 due the fact that the tests were conducted under constant mean effective stress and the model

374 captures such a behaviour (Figure 11). Overall the prediction of the model is in strong

375 agreement with the test data.

376 The results of the simulation of CIUC tests (Figure 9) are presented in Figure 12 and Figure

377 13, for loose and dense samples, respectively. These tests were conducted in undrained 378 conditions under 3 different confining pressures. The model predicts stiffer response initially,

379 but the overall response matches the experimental data very well, especially in $q-p^{\prime}$ plane.

380 Figure 14 and Figure 15 show the results of simulation of CADC tests under drained 381 conditions, during which samples of sand were first loaded isotropically to $p_{0}^{\prime}$, followed by a 382 loading under constant mean effective stress, followed by a standard triaxial loading to a 383 mean effective stress of $p_{1}^{\prime}$. The samples were then loaded to failure under constant mean 384 effective stress and under constant deviatoric stress, as shown in Figure 9 by $\mathrm{OO}_{1} \mathrm{~A}_{1} \mathrm{~A}_{2} \mathrm{C}_{2}$ and $385 \mathrm{OO}_{1} \mathrm{~A}_{1} \mathrm{~A}_{2} \mathrm{C}_{4}$ stress paths, respectively. The tests were performed at relative densities of $386 D_{r}=40 \%$ and $60 \%$. In both cases the model simulates the experimental behaviour very well.

387 The main features of the response, including the peak strength in $q-\varepsilon_{1}$ plane as well as the 388 initial contraction followed by the progressive dilation in $\varepsilon_{v}-\varepsilon_{1}$ plane were captured by the model. It is worth to mention that in CADC tests stress reversal occurs at point $A_{2}$ (refer to

390 Figure 9).

\section{Drained and Undrained Tests on Toyoura Sand}

392 Toyoura sand has been used extensively by scholars for verification of different constitutive 393 models (e.g. Khalili et al., 2005, Ling and Yang, 2006). In this study the experimental data on 
Toyoura sand reported by Verdugo and Ishihara (1996) are used to verify the performance of

395 the UNSW model. The material parameters obtained by calibration of the model with these 396 tests are also used later to evaluate the performance of the model in simulating a different 397 series of tests reported by Pradhan et al. (1989a). The material parameters used for simulation 398 of these tests are shown in Table 1and Table 2.

399 Verdugo and Ishihara (1996) performed a series of drained and undrained monotonic triaxial 400 tests on Toyoura sand. The specimens were prepared using moist placement method. In the 401 drained tests, two different confining pressures of 100 and $500 \mathrm{kPa}$ were used for specimens 402 with three different void ratios, ranging from 0.81 to 0.996 . The undrained tests were 403 conducted under a wider range of confining pressures, from 100 to $3000 \mathrm{kPa}$ with different 404 void ratios corresponding to relative densities of $D_{r}=16 \%$ to $64 \%$, corresponding to 405 consistencies from very loose to dense states for the soil under practical stress levels.

406 The results of the simulations of drained tests under $p_{0}^{\prime}=100 \mathrm{kPa}$ and $500 \mathrm{kPa}$ are shown in 407 Figure 16 and compared with experimental data. While there is a slight discrepancy between 408 the predicted performance and experimental data for the loose sample under the low confining 409 pressure, i.e. in test 3, the model predictions for other samples are in excellent agreement with 410 the observed data.

411 The performance and capability of the model to simulate the undrained behaviour of sands on 412 a wide range of initial conditions, including different relative densities and mean effective 413 stresses, are investigated using 7 undrained tests reported by Verdugo and Ishihara (1996). 414 The outcomes of these simulations are compared with the experimental data in Figure 17 for 415 mean effective stresses vary from 100 to $3000 \mathrm{kPa}$. In general, the comparison shows 416 satisfactory results, considering the fact that a single set of parameters is used for all 417 simulations under a large range of confining pressures. 
The parameters calibrated from the experiments of Verdugo and Ishihara (1996) are also used

419 to simulate the drained behaviour of Toyoura sand reported by Pradhan et al. (1989a). The experiments were conducted under various stress paths, including tests to failure under constant axial stress, constant mean effective stress and constant radial pressure, as well as conventional triaxial test (CTC) as shown in Figure 18

Figure 19 compares the results of simulations with the experimental data. The model captures all features of the soil behaviour for different stress paths, with some minor discrepancies where maximum large stress ratio is approached. This may be due to the fact that the Toyoura sand used by Pradhan et al. (1989a) was of a different batch from Verdugo and Ishihara (1996), and therefore requires slightly different parameters.

\section{Cyclic Drained tests on Toyoura sand}

430 Pradhan et al. (1989b) performed a series of drained triaxial cyclic tests on Toyoura sand.

431 Four cyclic drained tests with constant mean effective stress are selected and used in this 432 study. To highlight the robustness of the proposed model, the material parameters obtained 433 from model calibration with the experimental tests conducted by Verdugo and Ishihara (1996) 434 are used in these simulations. The state parameters and initial conditions of the samples are 435 presented inTable 3.

436 Figure 20 and Figure 21 show results of drained cyclic tests conducted under constant mean 437 effective stresses on loose and dense samples of Toyoura sand. In these tests the amplitude of 438 the shear strain increases during cyclic loading. These figures show that the model can 439 simulate well the stress-strain response and the successive stiffening or softening of the 440 samples with cyclic loading. The results of the simulation under higher stress levels match 441 better with the experimental data. This may be due the fact that the model parameters are 
obtained based on tests conducted on a range of stress levels, mostly greater than $1000 \mathrm{kPa}$,

443 which are greater than those used in Pradhan et al. (1989b) experimental tests, which are all 444 under $100 \mathrm{kPa}$.

445 Figure 22 shows the results of simulation of a drained cyclic test with a constant mean 446 effective stress on a very loose sample of Toyoura sand. In this test the amplitude of the shear 447 strain decreases during cyclic loading. This figure also shows the results of a simulation 448 performed by Ling and Yang (2006). The UNSW model captures the general behaviour 449 observed in the experiment, especially in the $\eta-\varepsilon_{q}$ plane. In $\varepsilon_{v}-\varepsilon_{q}$ plane the simulation 450 shows a lower volume change in the median cycles compared to the experimental data. Figure 45122 shows the superior performance of the model over that presented by Ling and Yang (2006).

452 Figure 23 represents the results of simulation of a drained cyclic test on a very loose sample 453 of Toyoura sand under a constant mean effective stress and small hysteresis loops of 454 unloading and reloading. Once again, the model predicts the main features of the behaviour, 455 both in $\eta-\varepsilon_{q}$ plane and $\varepsilon_{v}-\varepsilon_{q}$ plane. It is worth mentioning that a better match between the 456 results of simulation and the test data could have been achieved if the model parameters were 457 calibrated for the same test rather than taking from those calibrated for tests performed by 458 Verdugo and Ishihara (1996).

\section{Cyclic Undrained tests on Fuji River sand}

Ishihara et al. (1975) conducted a series of undrained triaxial cyclic tests on loose samples of Fuji River sand to study the liquefaction phenomena. Loose samples were obtained by

462 spooning freshly boiled sand into the mold filled with de-aired water. Two of these tests are 463 selected for simulation to show the performance of UNSW model in capturing the undrained 464 behaviour of granular materials. The material parameters and the initial conditions of the samples are listed in Table 1 and 
466 Table 3, respectively. A constant value of $k_{m}$ is used in these simulations due to the narrow 467 range of initial state parameters, as shown in Table 2.

468 Figure 24 presents the results of the undrained test conducted on loose Fuji River sand under a 469 cyclic loading with constant stress amplitude. Figure 25 shows the results for a test under 470 irregular cyclic stress amplitude. In both simulations the predicted behaviour is in good 471 agreement with the observed experimental data. The model captures the failure of the samples 472 by liquefaction in which the effective normal stress decreases progressively until the stress 473 path reaches the critical state and the material becomes unstable.

\section{CONCLUSION}

The UNSW bounding surface plasticity model has been proved to be a versatile constitutive model capable of simulating the behaviour of sands over a wide range of stresses under drained/undrained and monotonic/cyclic loading conditions. A relatively complex mapping rule was initially formulated for the model which makes application of the model to simulation of highly variable cyclic loading inefficient. In this study, a new mapping rule is formulated which is less complex and more efficient for simulation of complex monotonic and cyclic loadings of granular soils. The new mapping rule does not require a record of history of successive intermediate local bounding surfaces, as was required in the original mapping rule. Comparison of the results of simulations of the model using the original and the new mapping rules indicated that the simplification incorporated in the new mapping rule does not compromise the performance of the model. The robustness of the UNSW model with the new mapping rule was demonstrated through simulations of static and cyclic loading under drained and undrained conditions for different soils. The results of simulations were invariably in excellent agreement with experimental data. The model captures the 
stresses, including the stress softening and dilatancy during drained loading of dense sands, liquefaction of loose sands under undrained loading conditions, and the progressive stiffening as well as hysteresis in the stress-strain relationships for cyclic loading. The versatility of the model in simulation of particular sand was demonstrated using one set of material parameters for all tests conducted on the sand under different conditions and by different investigators.

\section{Acknowledgements}

The first author is the recipient of the Endeavour Postgraduate Award, Funded by the Australian Government via Department of Education, Employment and Workplace Relations (DEEWR). The support of DEEWR is gratefully acknowledged.

\section{References}

Arulmoli, K., Muraleetharan, K., Hossain, M., \& Fruth, L. (1992). VELACS: Verification of liquefaction analyses by centrifuge studies, laboratory testing program, soil data report. Research Report, The earth Technology Corporation.

Bardet, J. (1986). Bounding surface plasticity model for sands. Journal of Engineering Mechanics, 112(11), 1198-1217.

Been, K., Jefferies, M., \& Hachey, J. (1991). The critical state of sands. Geotechnique, 41(3), 365-381.

Chen, Y. R. (1995). Behavior of a fine sand in triaxial, torsional and rotational shear tests. PhD thesis, University of California, Davis.

Crouch, R. S. (1994). Unified Critical State Bounding Surface Plasticity Model for Soil. Journal of Engineering Mechanics, 120(11), 2251-2270. 
Crouch, R. S., \& Wolf, J. P. (1994a). Unified 3D critical state bounding surface plasticity model for soils incorporating continuous plastic loading under cyclic paths. Part II: Calibration and simulations. International Journal for Numerical and Analytical Methods in Geomechanics, 18(11), 759-784.

Crouch, R., \& Wolf, J. (1994b). Unified 3D critical state bounding-surface plasticity model for soils incorporating continuous plastic loading under cyclic paths. Part I: constitutive relations. International Journal for Numerical and Analytical Methods in Geomechanics, 18(11), 735-758.

Dafalias, Y., \& Popov, E. (1975). A model of nonlinearly hardening materials for complex loading. Acta Mechanica, 21(3), 173-192.

Dafalias, Y. F., \& Herrmann, L. R. (1980). A bounding surface soil plasticity model. International Symposium on Soils under Cyclic and Transient Loading, Swansea.

Dowell, M., \& Jarratt, P. (1972). The "Pegasus" method for computing the root of an equation. BIT Numerical Mathematics, 12(4), 503-508.

Ishihara, K., Tatsuoka, F., \& Yasuda, S. (1975). Undrained deformation and liquefaction of sand under cyclic stresses. Soils and Foundations, 15(1), 29-44.

Khalili, N., Habte, M., \& Valliappan, S. (2005). A bounding surface plasticity model for cyclic loading of granular soils. International journal for numerical methods in engineering, 63(14), 1939-1960.

Khalili, N., Habte, M., \& Zargarbashi, S. (2008). A fully coupled flow deformation model for cyclic analysis of unsaturated soils including hydraulic and mechanical hystereses. Computers and Geotechnics, 35(6), 872-889.

Krieg, R. (1975). A practical two surface plasticity theory. Journal of applied mechanics, ASME, 42, 641. 
Kutter, B. L., Chen, Y. R., \& Shen, C. (1994). Triaxial and torsional shear test results for sand, Contract Report CR 94.003-SHR, Naval Facilities Engineering Service Center. Port Hueneme, CA 93043-4328.

Ling, H. I., \& Yang, S. (2006). Unified sand model based on the critical state and generalized plasticity. Journal of Engineering Mechanics, 132(12), 1380-1391.

Pastor, M., Zienkiewicz, O., \& Chan, A. (1990). Generalized plasticity and the modelling of soil behaviour. International Journal for Numerical and Analytical Methods in Geomechanics, 14(3), 151-190.

Pradhan, T., Tatsuoka, F., Mohri, Y., \& Sato, Y. (1989a). An atomated triaxial testing system using a simple triaxial cell for soils. Soils and Foundations, 29(1), 151-160.

Pradhan, T., Tatsuoka, F., \& Sato, Y. (1989b). Experimental stress-dilatancy relations of sand subjected to cyclic loading. Soils and Foundations, 29(1), 45-64.

Russell, A. R., \& Khalili, N. (2004). A bounding surface plasticity model for sands exhibiting particle crushing. Canadian Geotechnical Journal, 41(6), 1179-1192.

Russell, A., \& Khalili, N. (2006). A unified bounding surface plasticity model for unsaturated soils. International Journal for Numerical and Analytical Methods in Geomechanics, 30(3), 181-212.

Saada, A., Puccini, P., \& Bianchini, G. (1989). Information package. In A. Saada \& G. Bianchini (Eds.), Constitutive Equations for Granular Non-Cohesive Soils, pp. 81-87. Rotterdam: Balkema.

Sheng, D., Sloan, S., \& Yu, H. (2000). Aspects of finite element implementation of critical state models. Computational mechanics, 26(2), 185-196. 
557 Sloan, S. W., Abbo, A. J., \& Sheng, D. (2001). Refined explicit integration of elastoplastic 558 models with automatic error control. Engineering Computations, 18(1/2), 121-194.

559 Tatsuoka, F., \& Ishihara, K. (1974). Drained deformation of sand under cyclic stresses reversing direction. Soils and Foundations, 14(3), 51-65.

561 Verdugo, R., \& Ishihara, K. (1996). The steady state of sandy soils. Soils and Foundations, $36(2), 81-91$.

563 


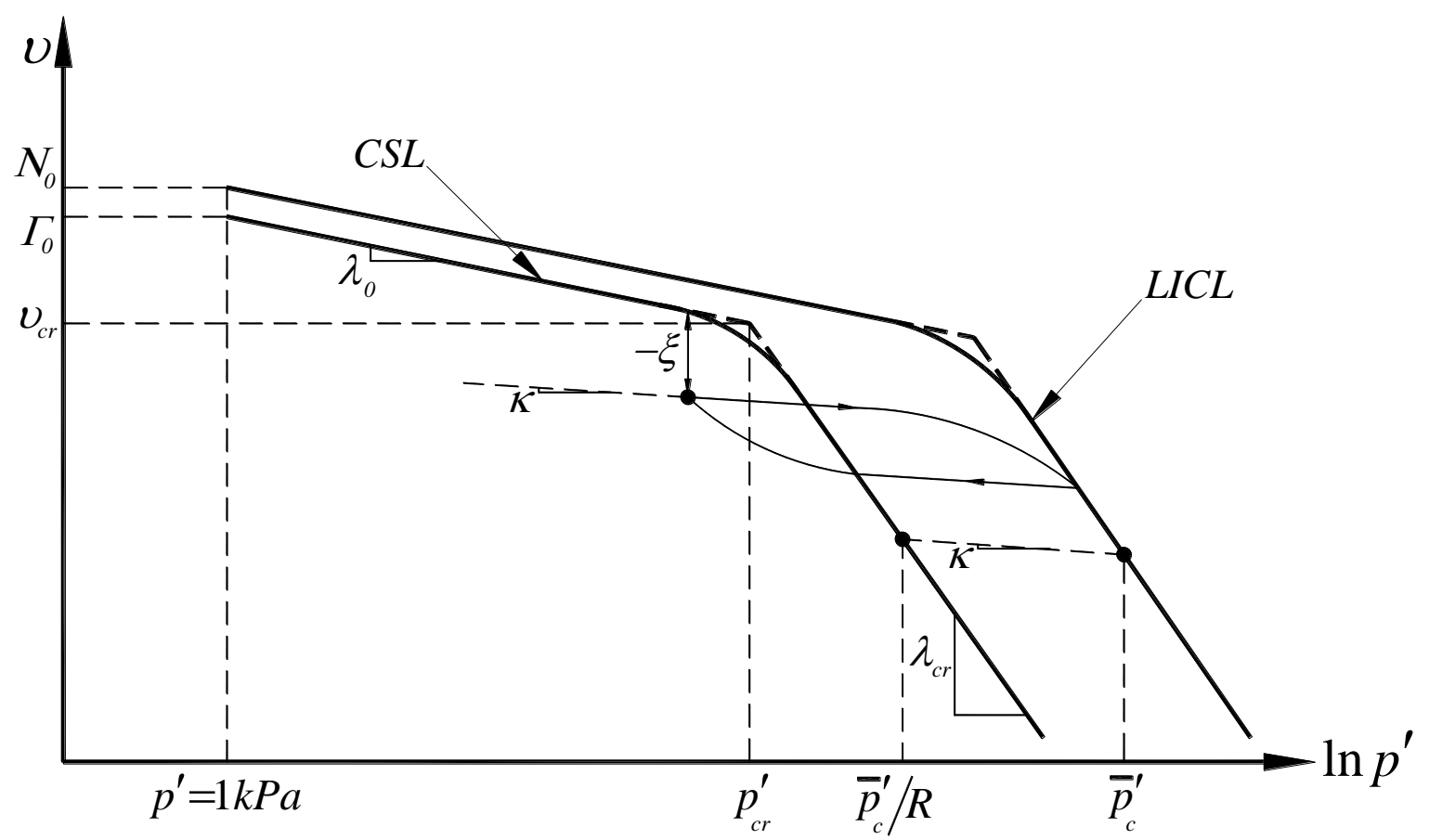

Figure 1: Critical State Line (CSL) and Limiting Isotropic Compression Line (LICL) 


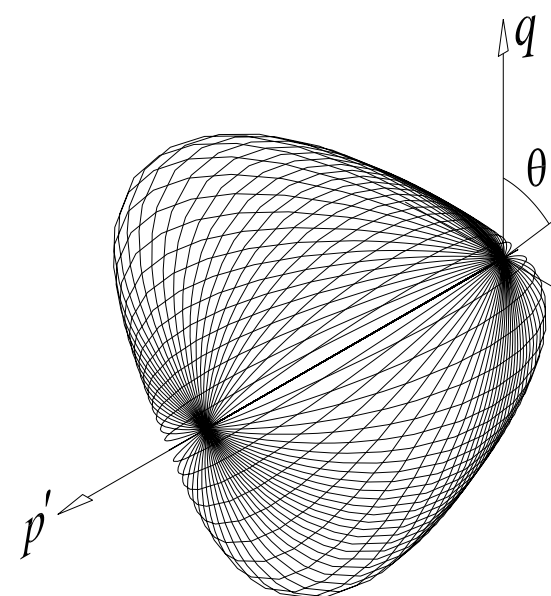

$N=2.0, R=2.0$

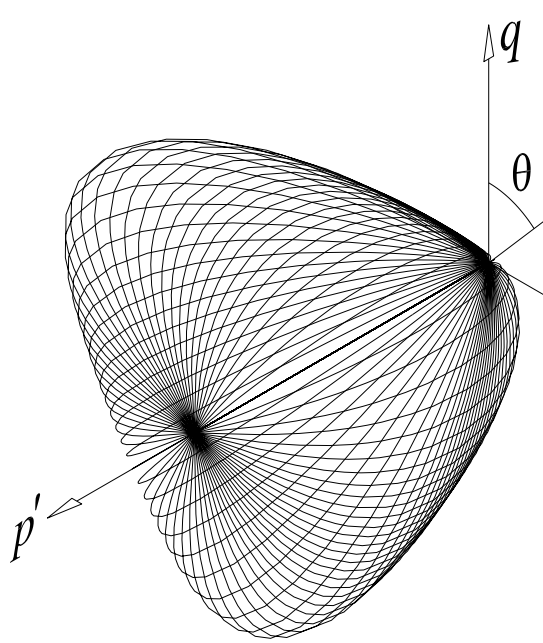

$$
N=3.0, R=2.0
$$

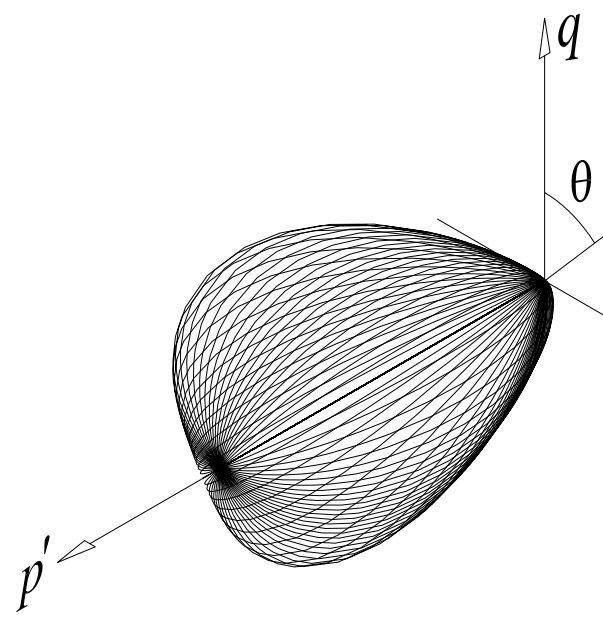

$$
N=2.0, R=6.0
$$

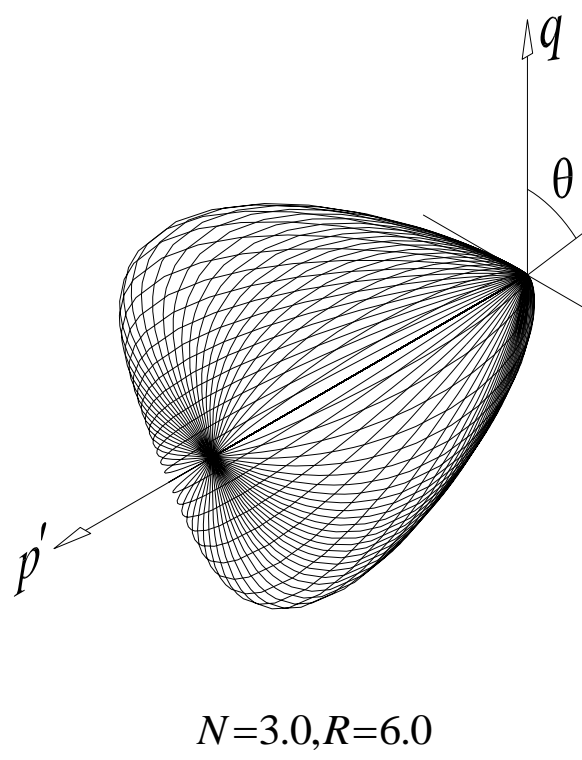




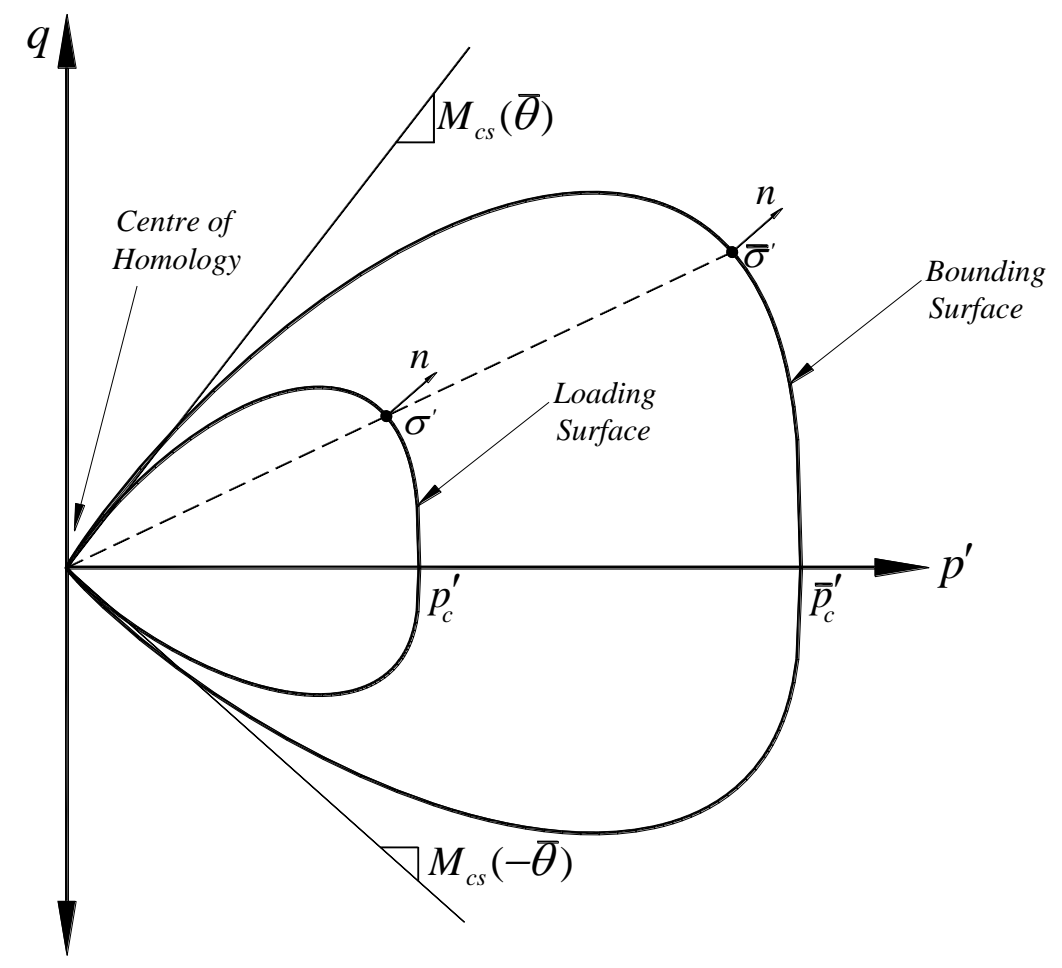




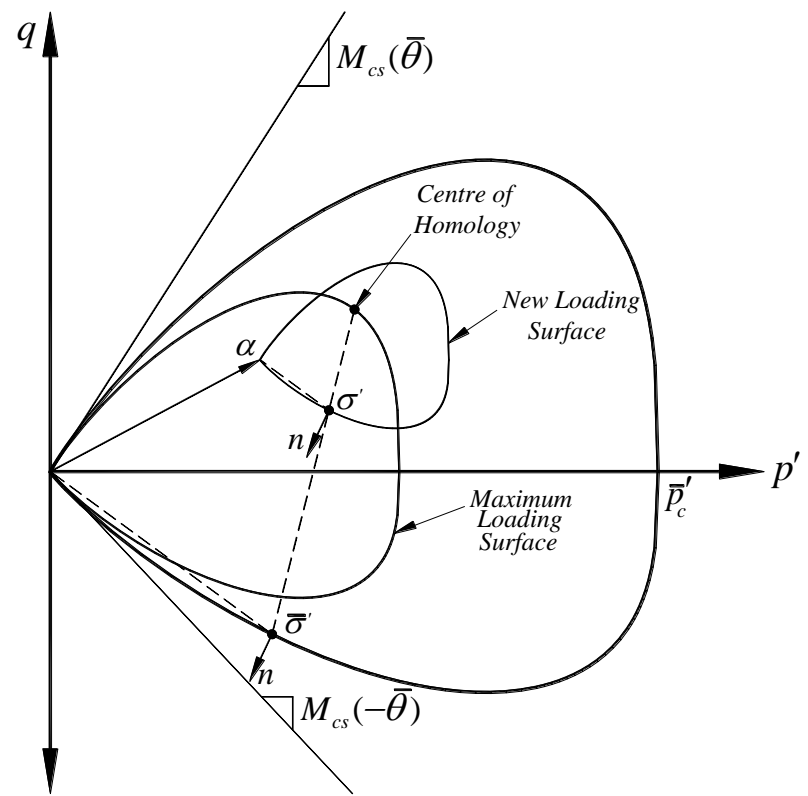

(a)

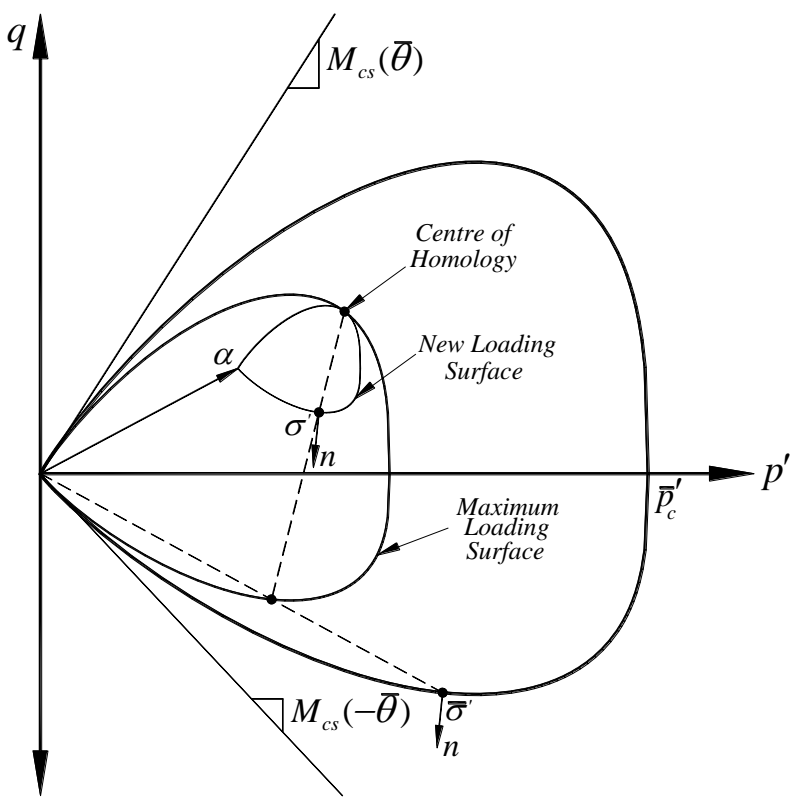

(b)

Figure 4: Loading surface and mapping rule for unloading/reloading

(a) current study, (b) Khalili et al. (2005) 


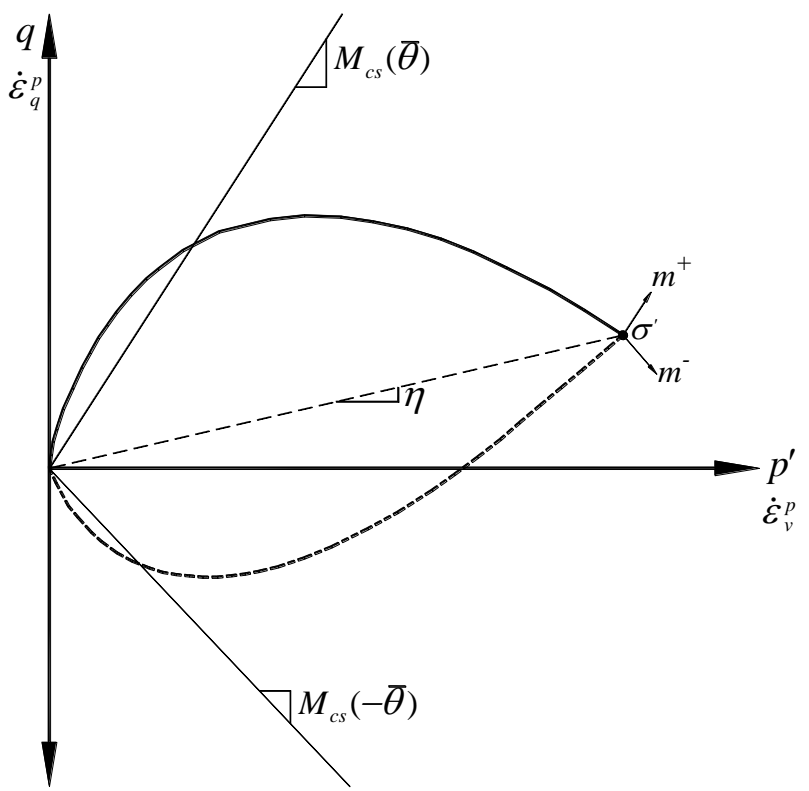

Figure 5: Vectors of plastic potential at $\sigma^{\prime}$ for compressive and extensive loading 
(a)
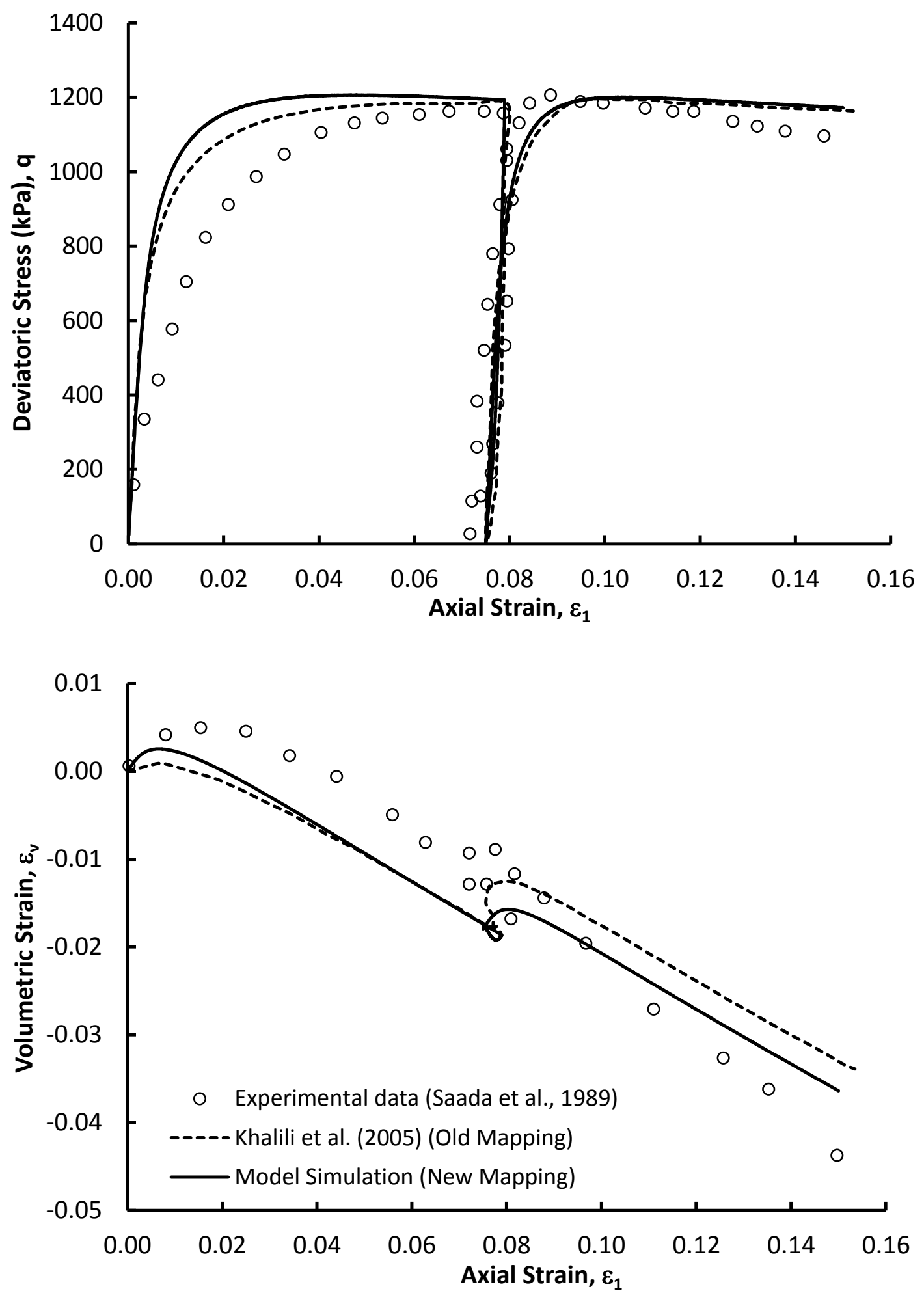

Figure 6: Drained cyclic test on a dense sample of Hostun sand

(a) $q-\varepsilon_{1}$ plot and (b) $\varepsilon_{v}-\varepsilon_{1}$ plot 

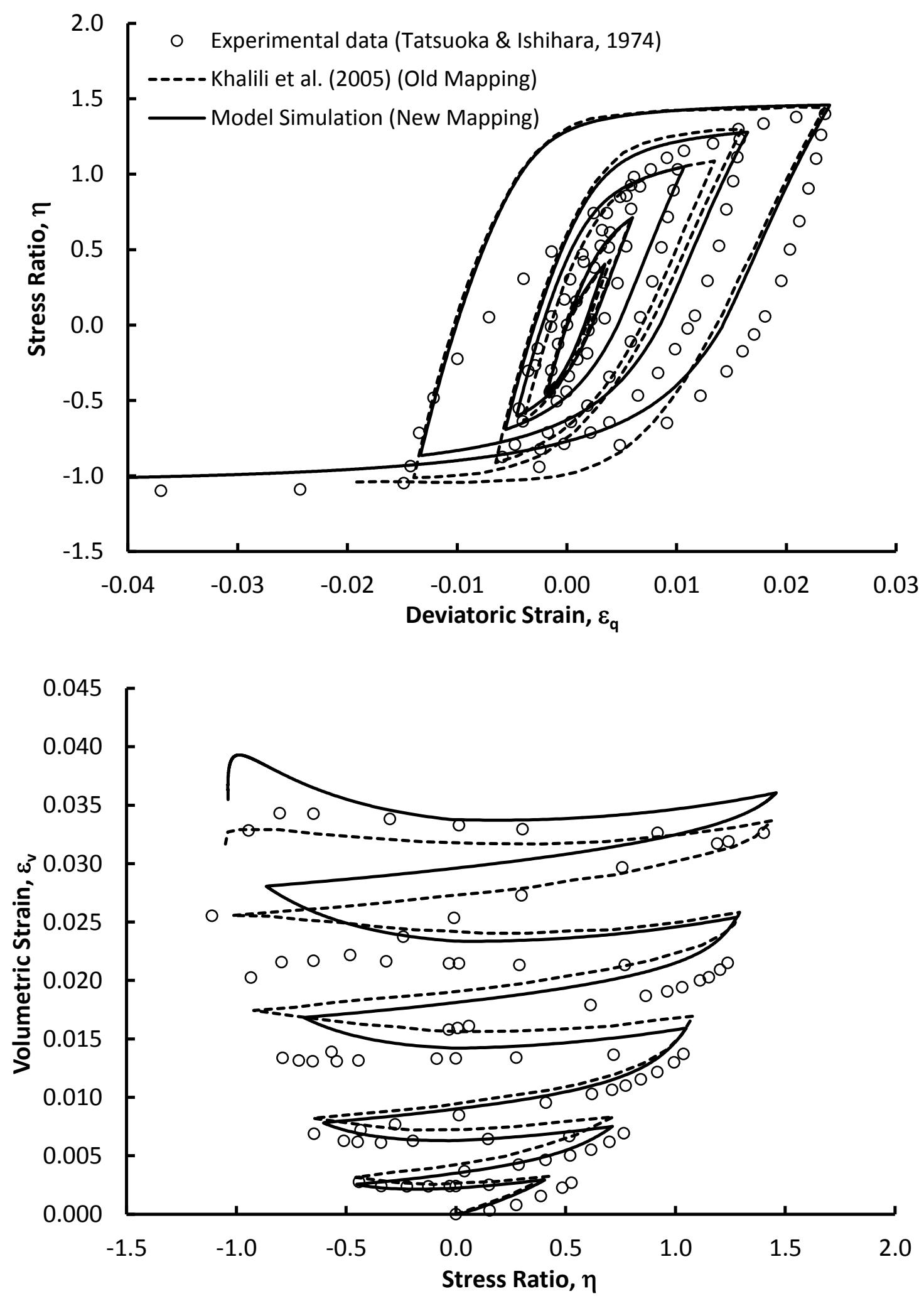

Figure 7: Drained cyclic test on a loose sample of Fuji River sand

(a) $\eta-\varepsilon_{q}$ plot and (b) $\varepsilon_{v}-\eta$ plot 

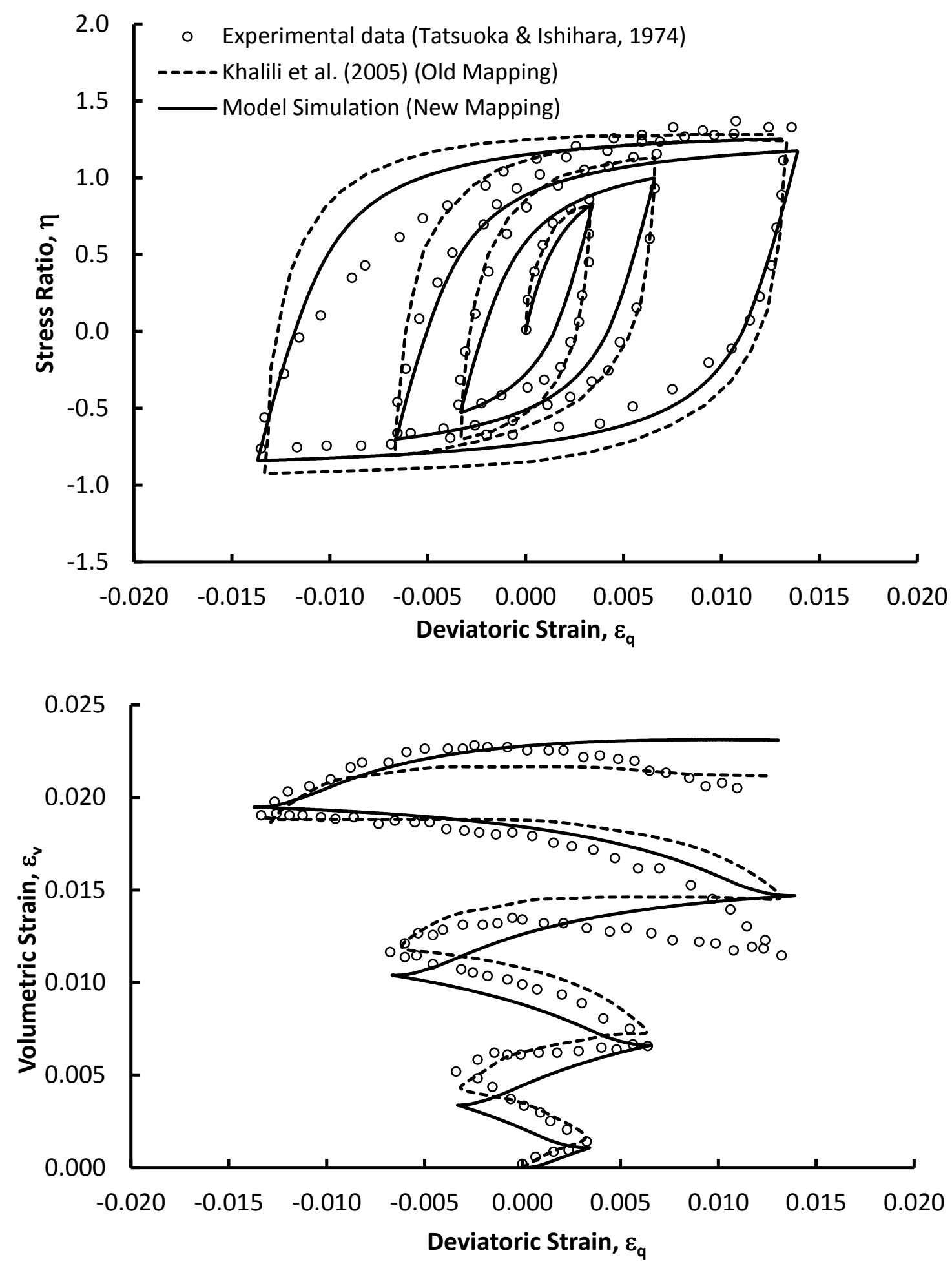

Figure 8: Drained cyclic test on a loose sample of Toyoura sand

(a) $\eta-\varepsilon_{q}$ plot and (b) $\varepsilon_{v}-\varepsilon_{q}$ plot 


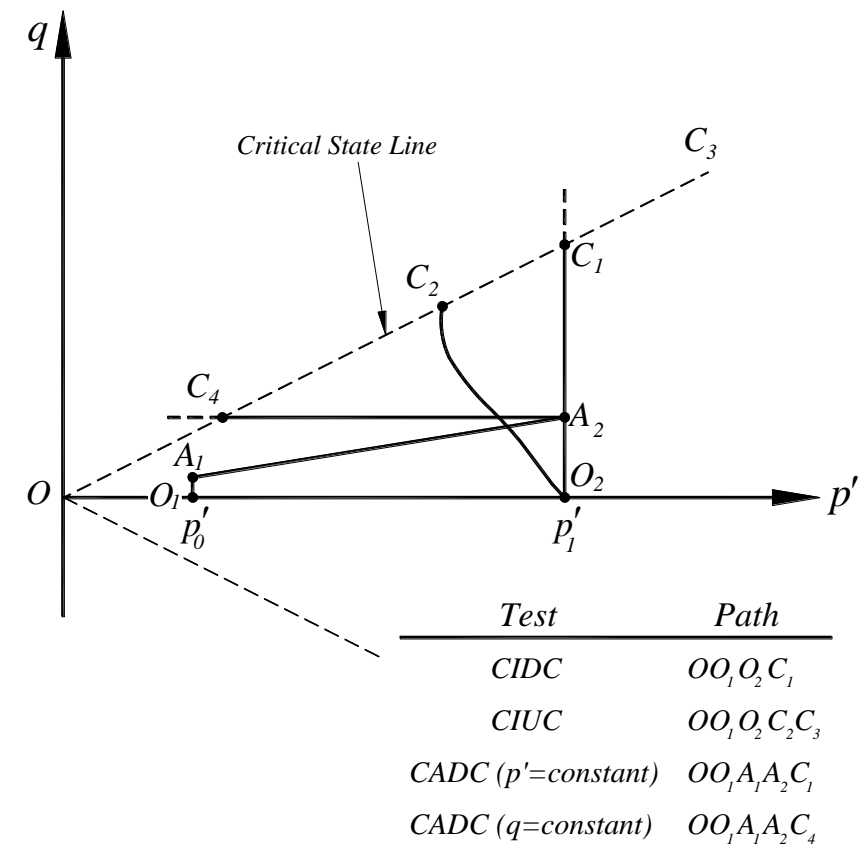

Figure 9: Stress paths in monotonic tests on Nevada Sand

(After Arulmoli et al., 1992) 
(a)
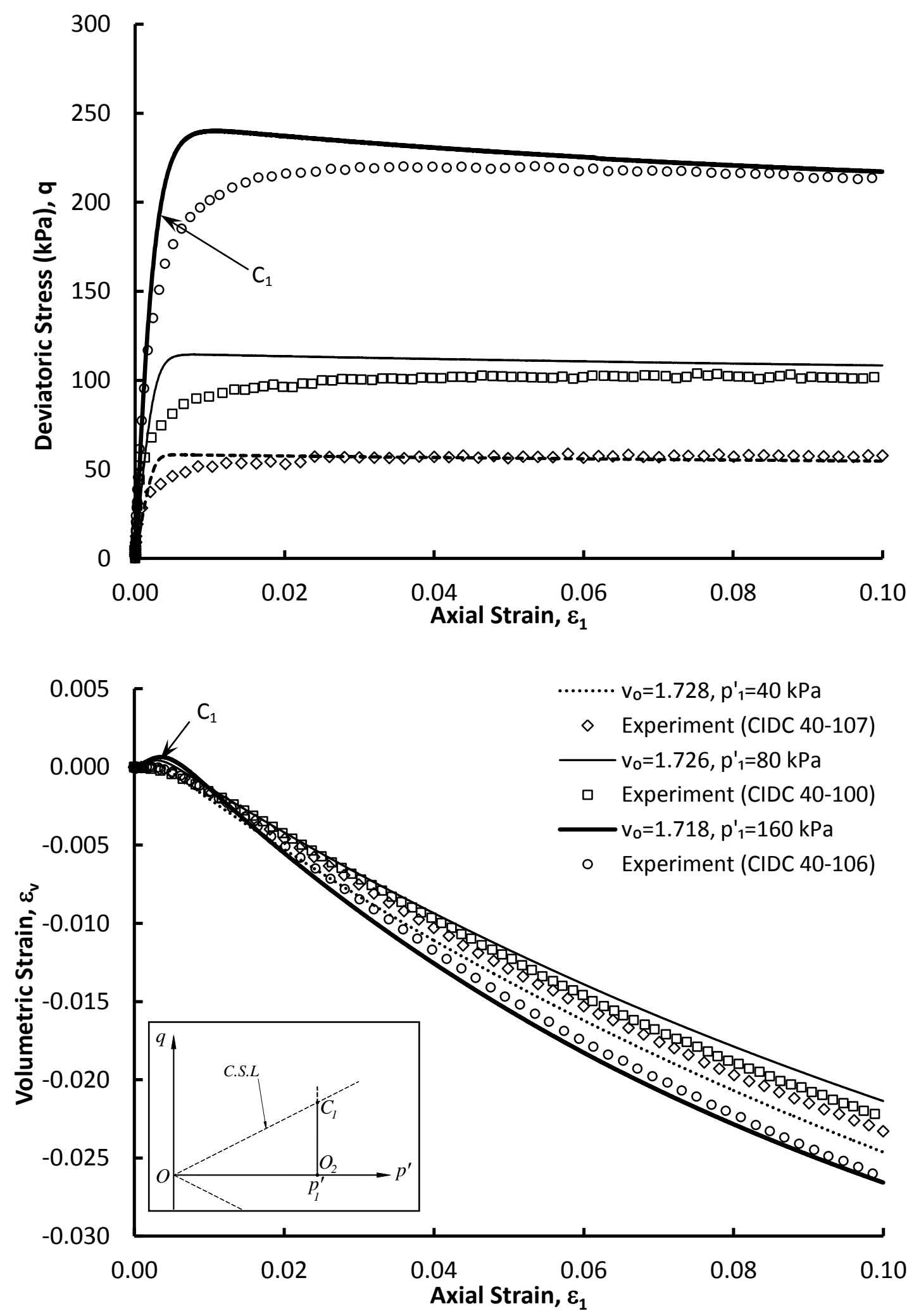

Figure 10: Drained CIDC tests on loose samples of Nevada sand $\left(D_{r}=40 \%\right)$

(a) $q-\varepsilon_{1}$ plot and (b) $\varepsilon_{v}-\varepsilon_{1}$ plot 
(a)
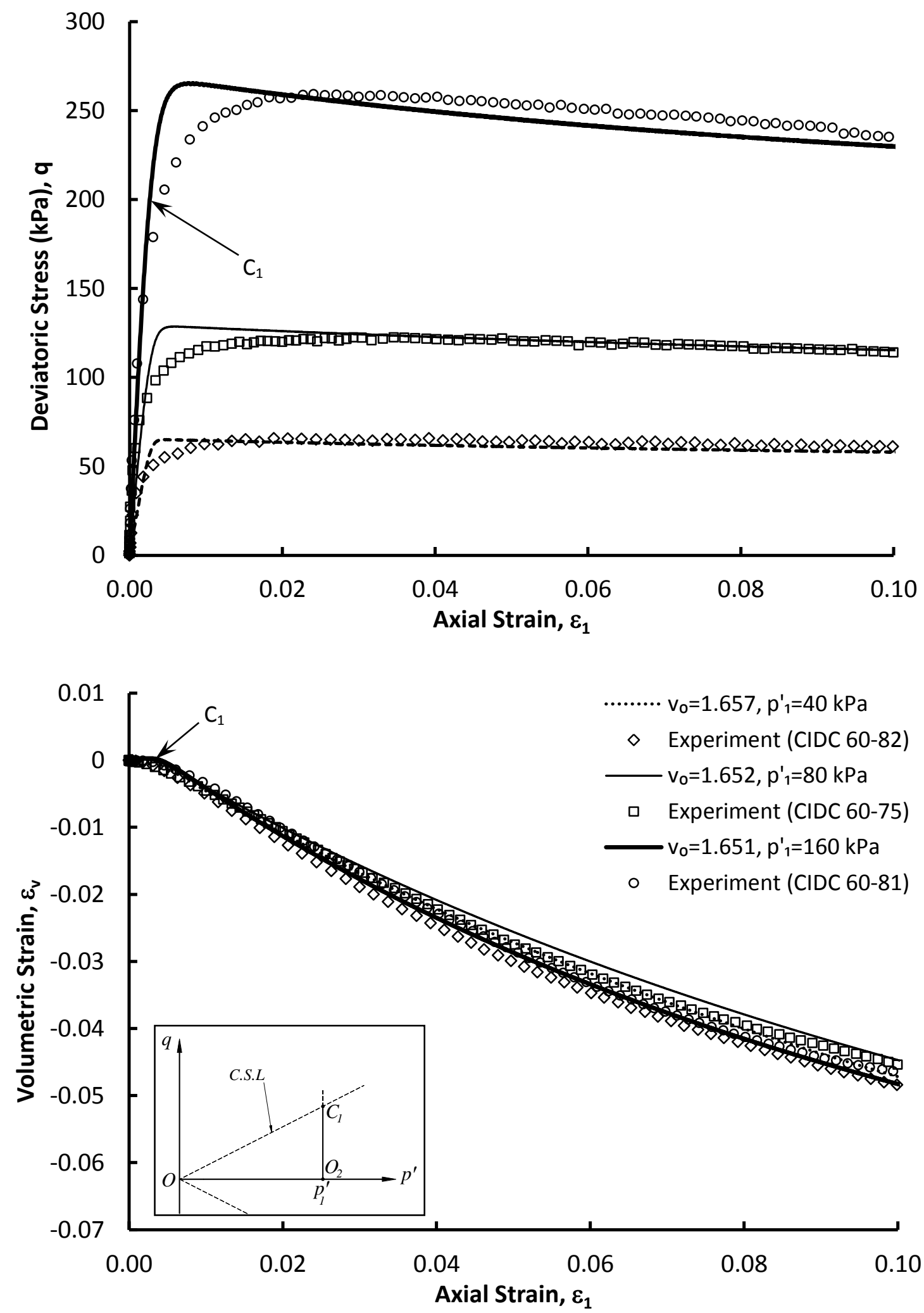

Figure 11: Drained CIDC tests on dense samples of Nevada sand $\left(D_{r}=60 \%\right)$

(a) $q-\varepsilon_{1}$ plot and (b) $\varepsilon_{v}-\varepsilon_{1}$ plot 
(a)

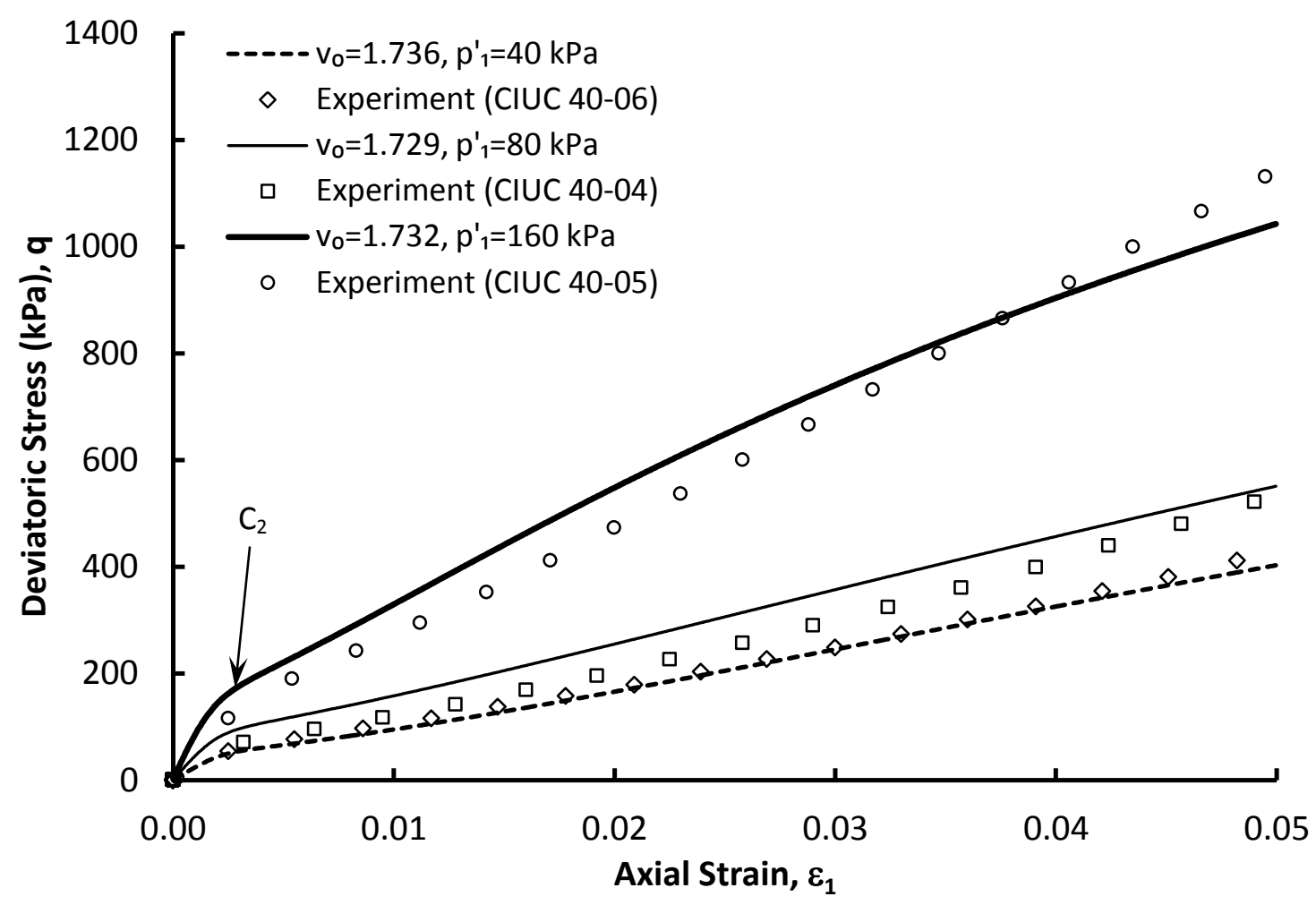

(b)

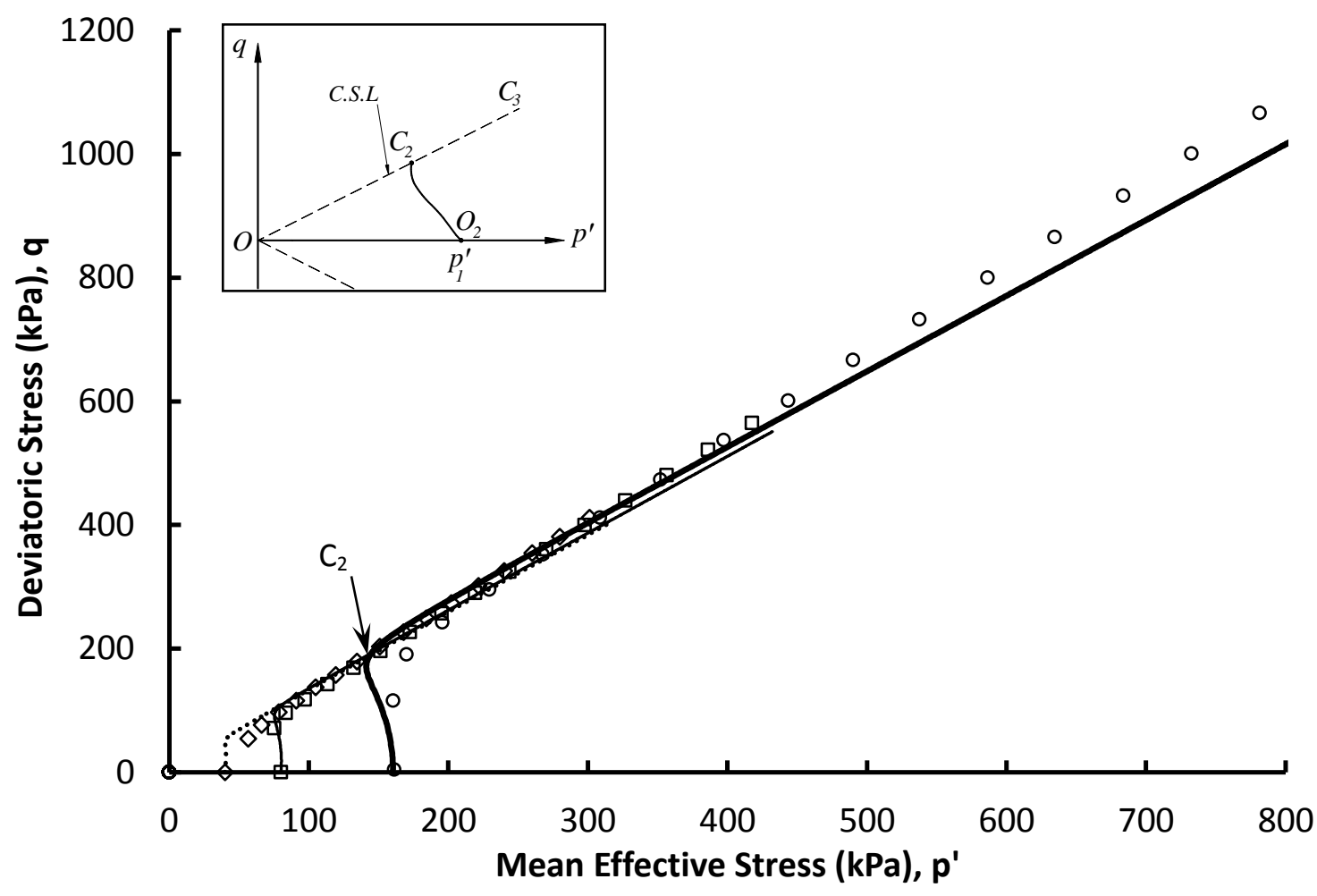

Figure 12: Undrained CIUC tests on loose samples of Nevada sand $\left(D_{r}=40 \%\right)$

(a) $q-\varepsilon_{1}$ plot and (b) $q-p^{\prime}$ plot 

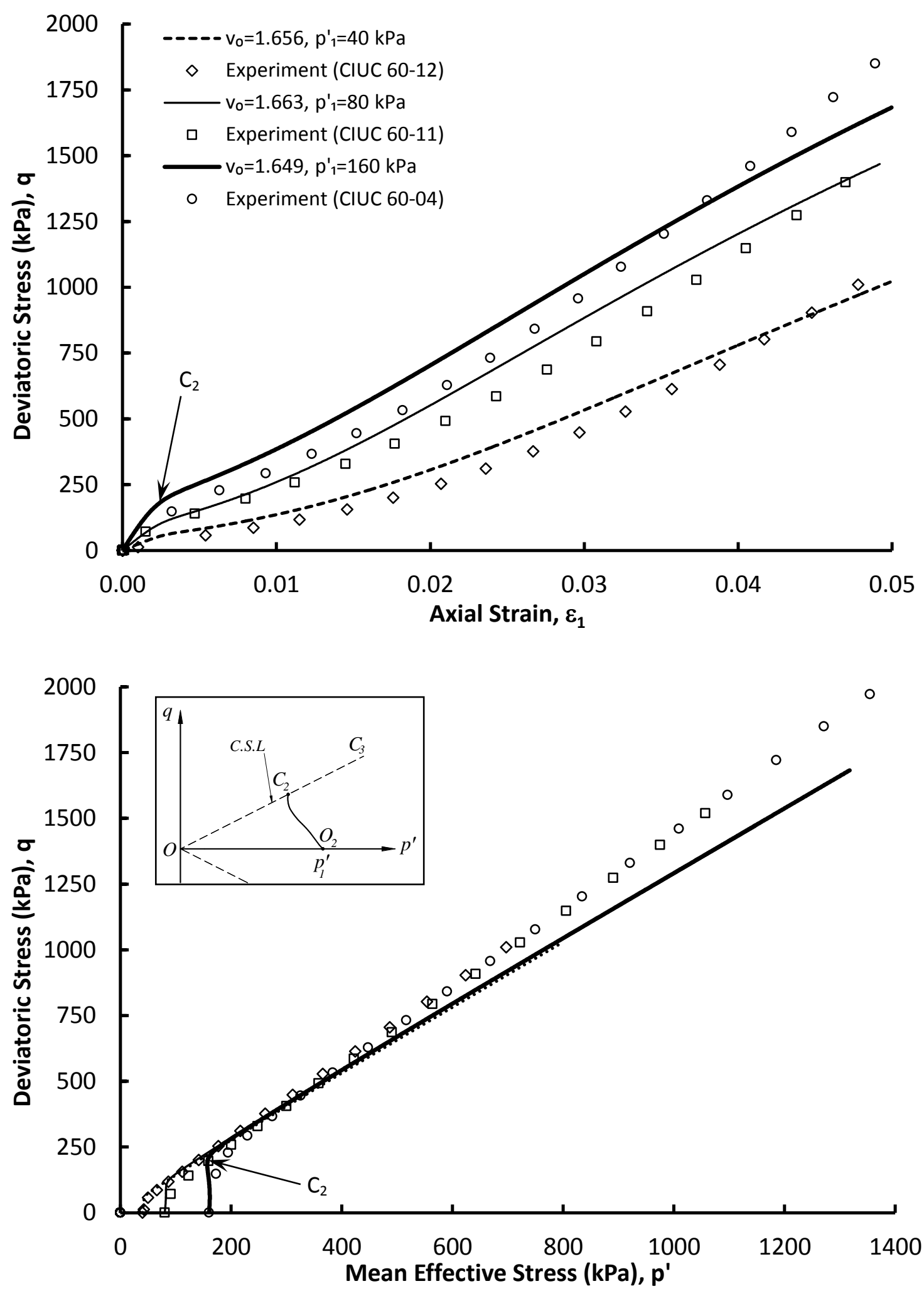

Figure 13: Undrained CIUC tests on dense samples of Nevada sand $\left(D_{r}=60 \%\right)$

(a) $q-\varepsilon_{1}$ plot and (b) $q-p^{\prime}$ plot 

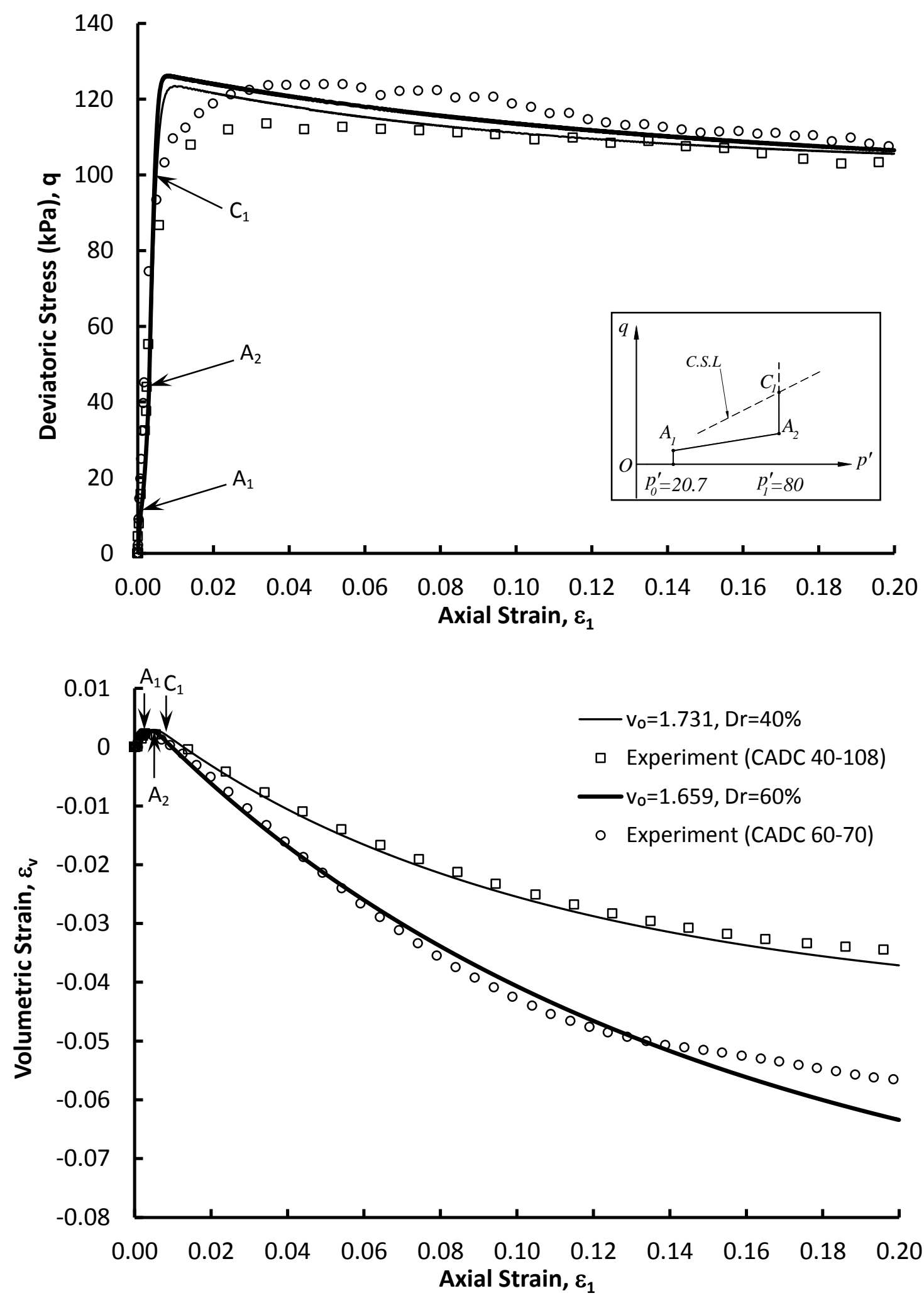

Figure 14: Drained CADC tests with constant $p^{\prime}$ on Nevada sand

(a) $q-\varepsilon_{1}$ plot and (b) $\varepsilon_{v}-\varepsilon_{1}$ plot 
(a)
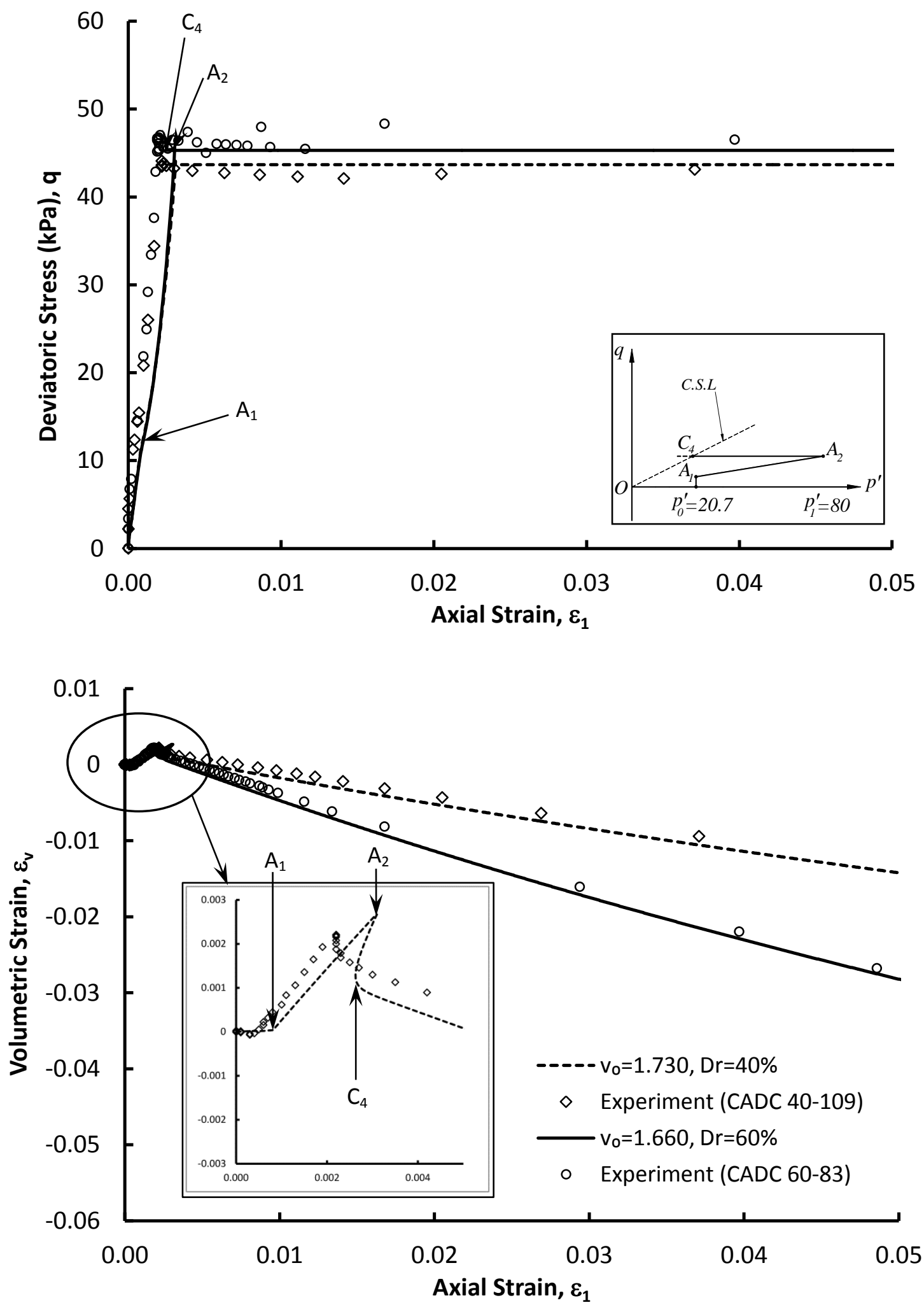

Figure 15: Drained CADC tests with constant $q$ on Nevada sand

(a) $q-\varepsilon_{1}$ plot and (b) $\varepsilon_{v}-\varepsilon_{1}$ plot 

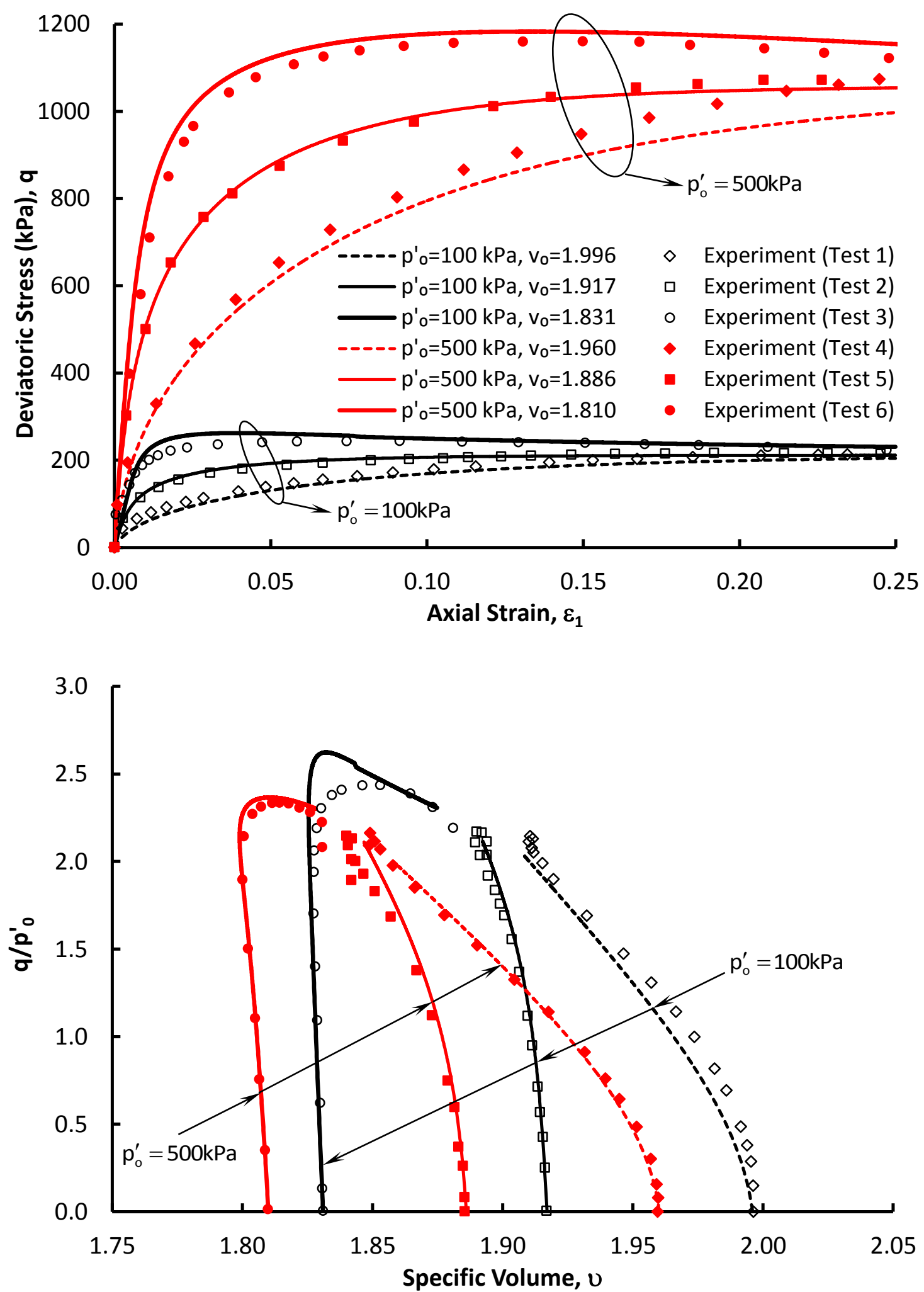

Figure 16: Drained tests on Toyoura sand

(a) $q-\varepsilon_{1}$ plot and (b) $q / p_{0}^{\prime}-v$ plot 

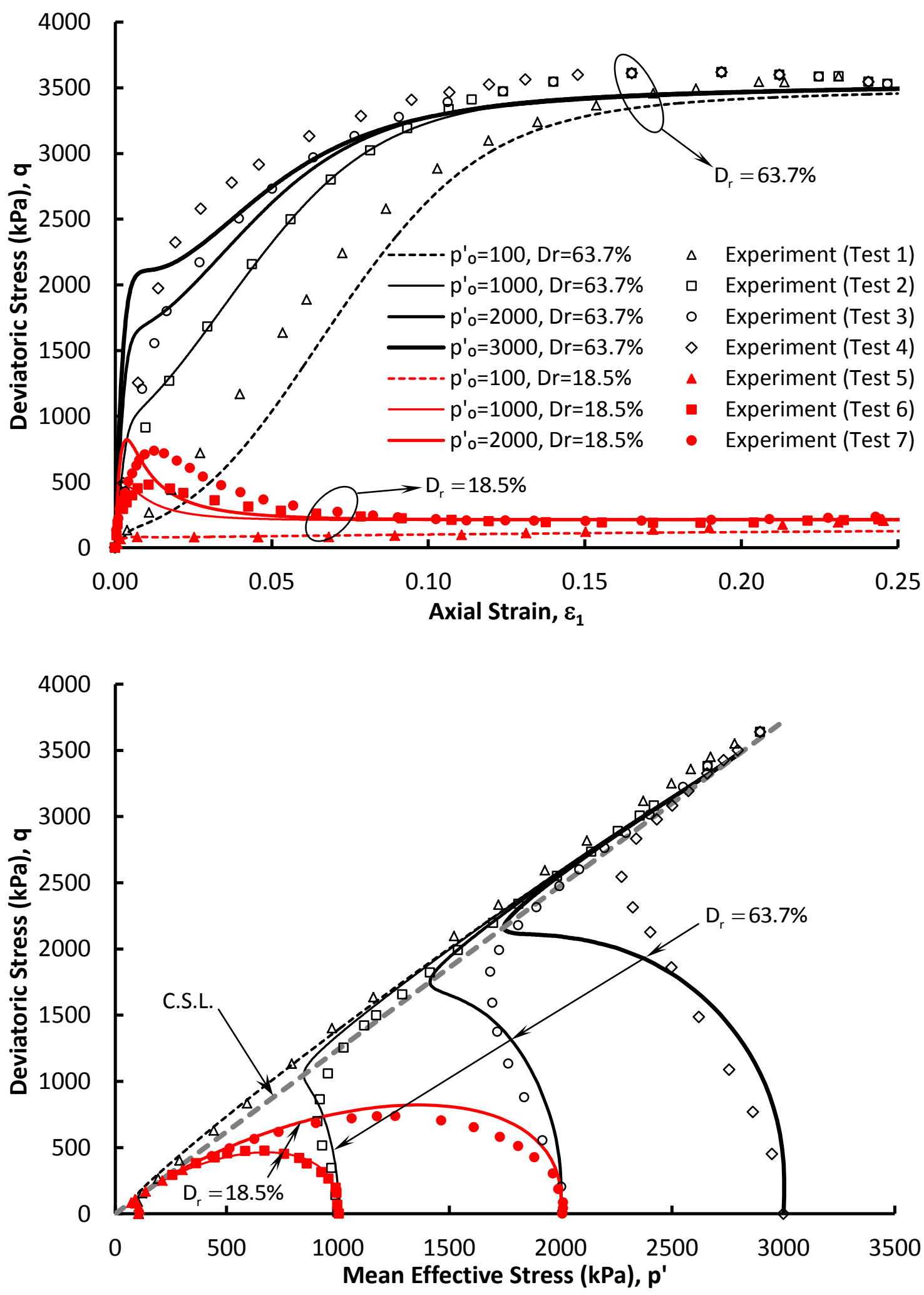

Figure 17: Undrained tests on Toyoura sand

(a) $q-\varepsilon_{1}$ plot and (b) $q-p^{\prime}$ plot 


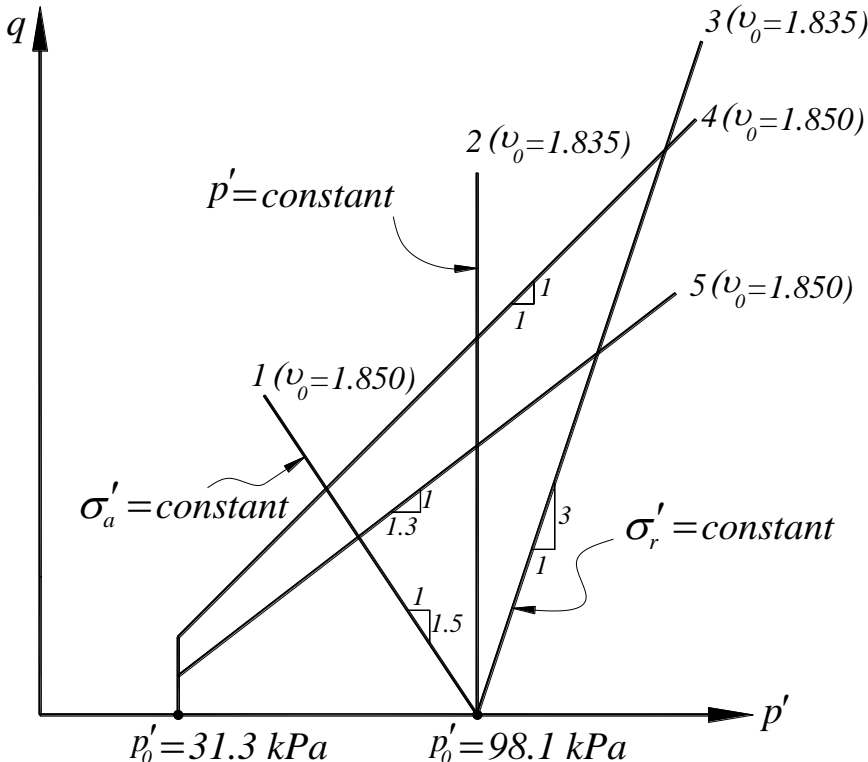



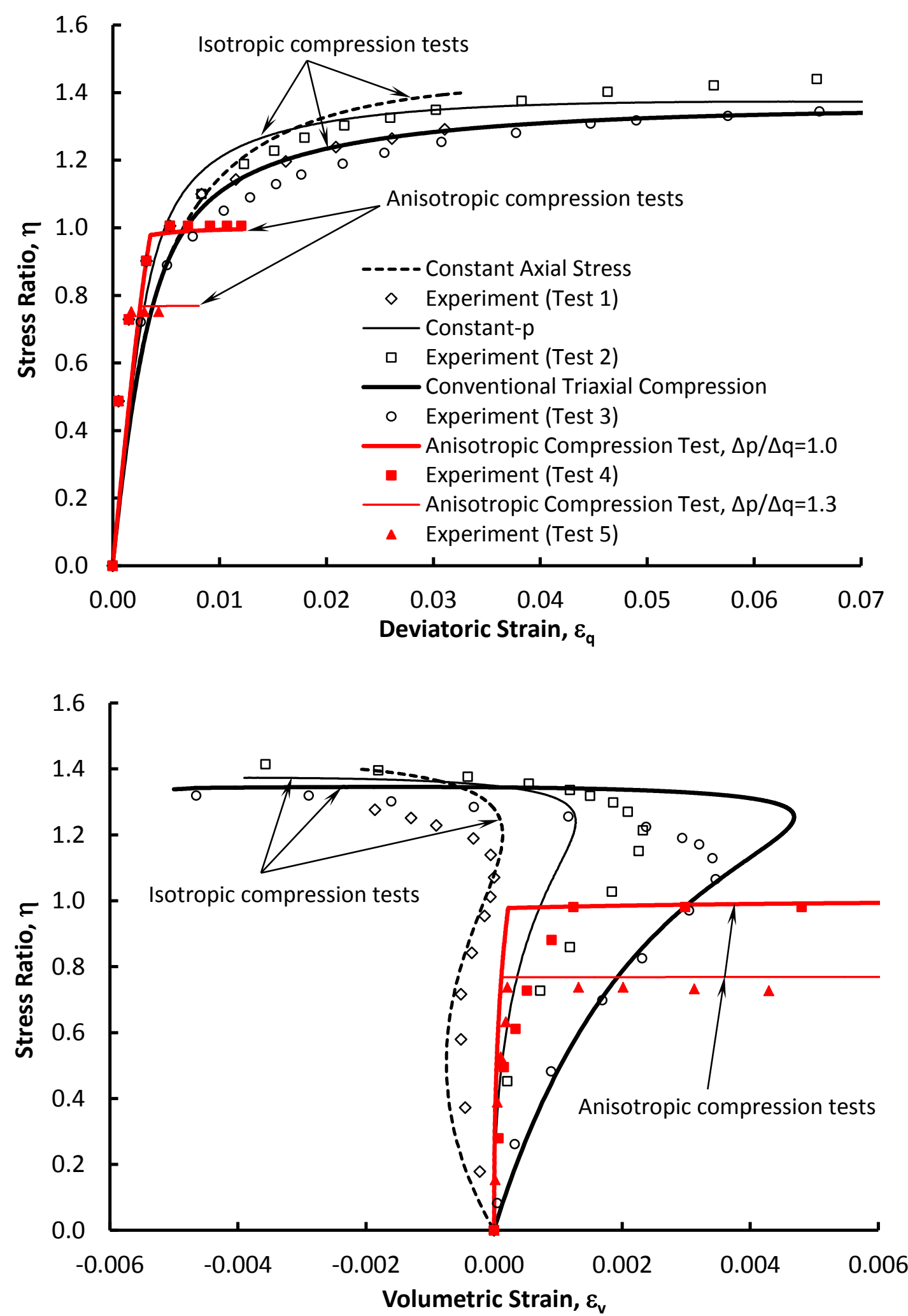

Figure 19: Drained tests with various stress paths on Toyoura sand

(a) $\eta-\varepsilon_{q}$ plot and (b) $\eta-\varepsilon_{v}$ plot 

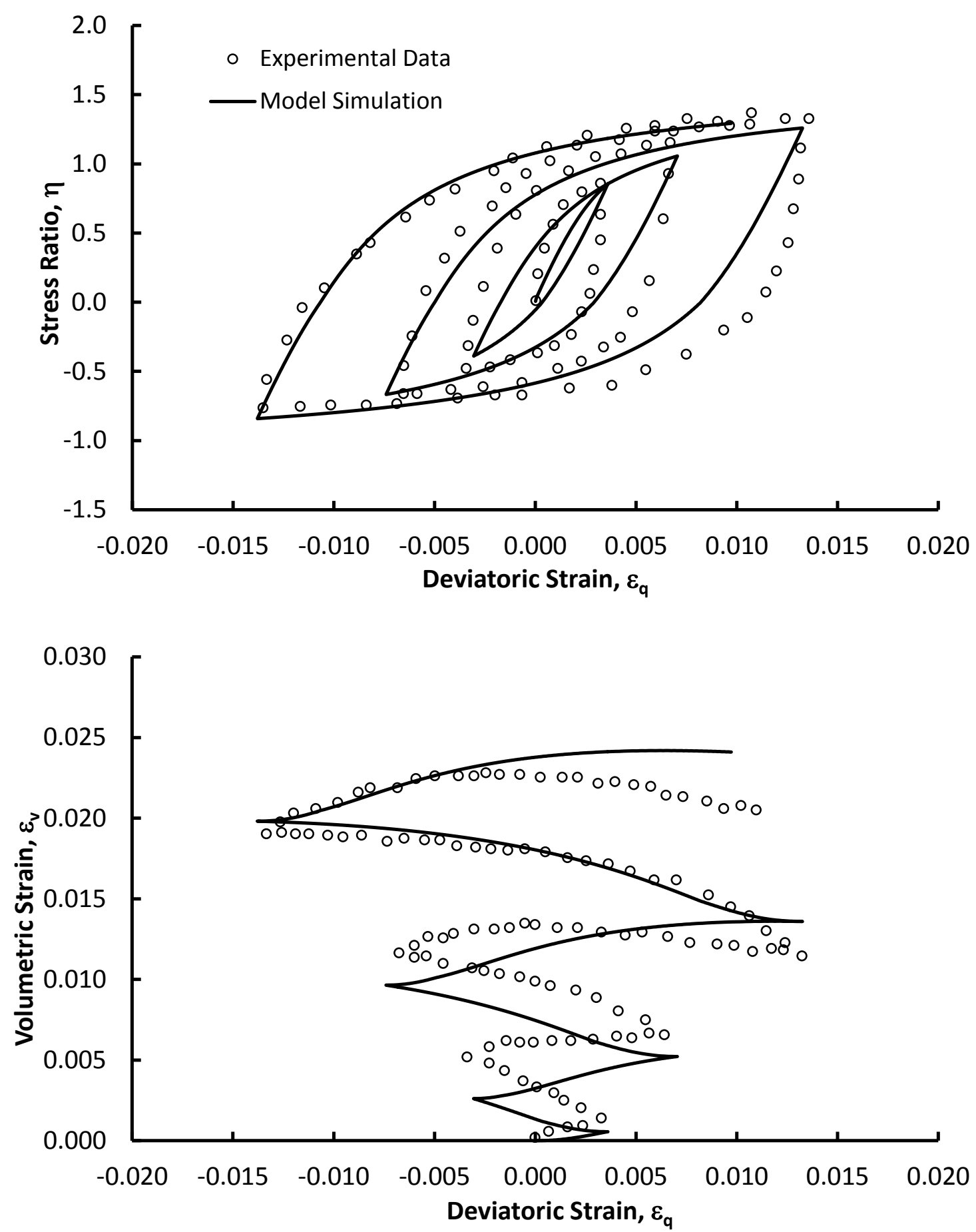

(b)

Figure 20: Drained cyclic test on a loose sample of Toyoura sand with increasing shear strain amplitude

(a) $\eta-\varepsilon_{q}$ plot and (b) $\varepsilon_{v}-\varepsilon_{q}$ plot 

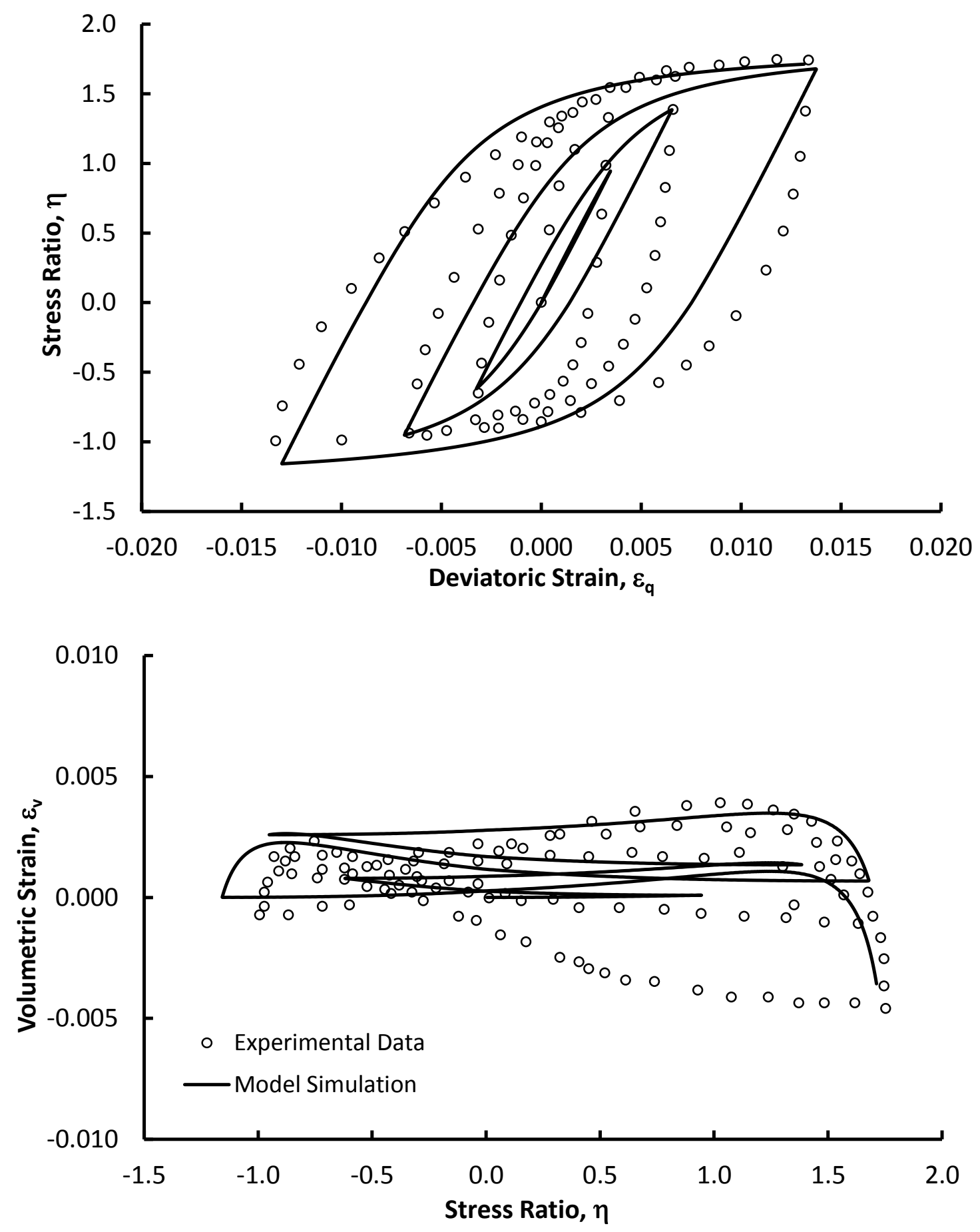

(b)

Figure 21: Drained cyclic test on a dense sample of Toyoura sand with increasing shear strain amplitude

(a) $\eta-\varepsilon_{q}$ plot and (b) $\varepsilon_{v}-\eta$ plot 

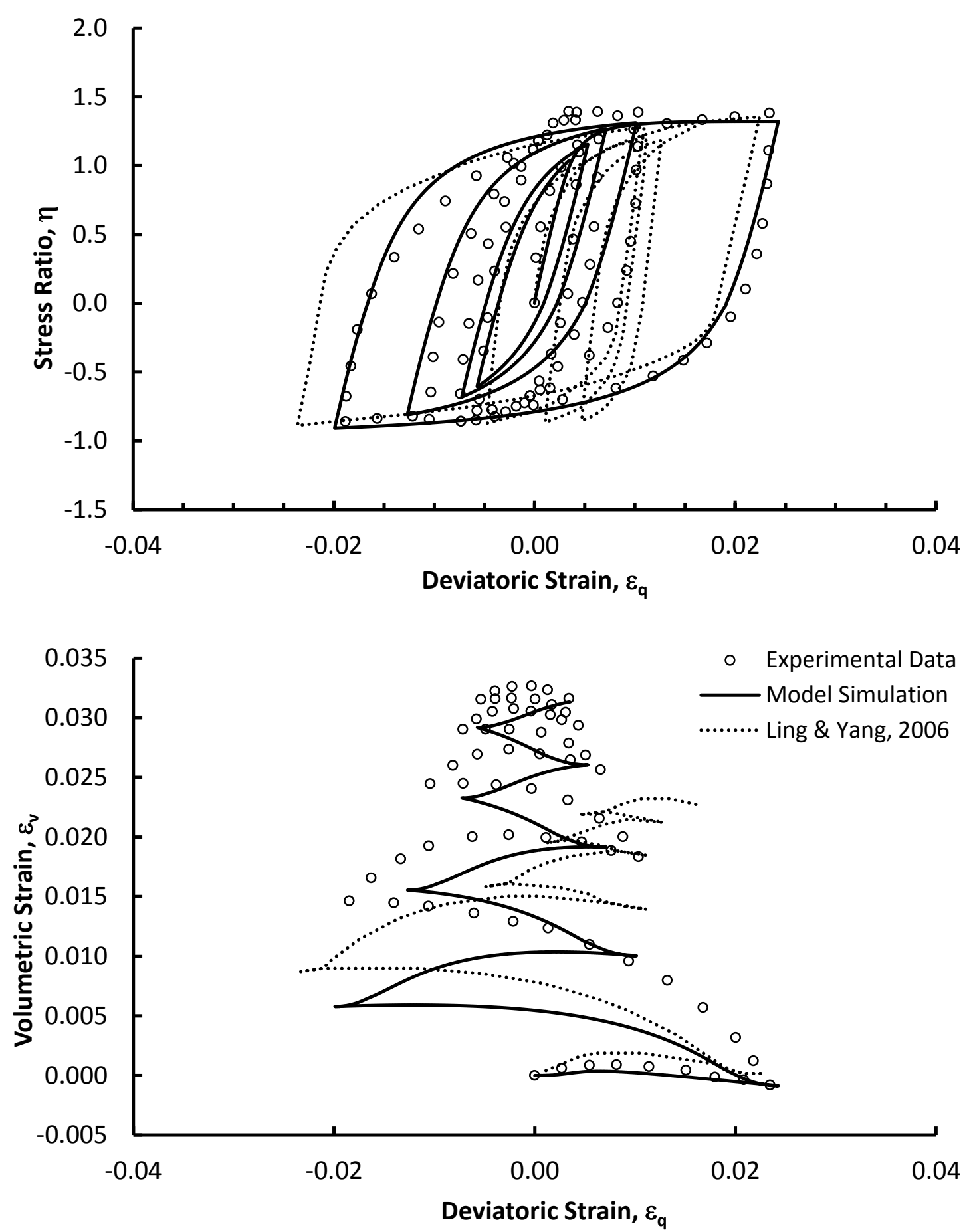

(b)

Figure 22: Drained cyclic test on a very loose sample of Toyoura sand with decreasing shear strain amplitude

(a) $\eta-\varepsilon_{q}$ plot and (b) $\varepsilon_{v}-\varepsilon_{q}$ plot 

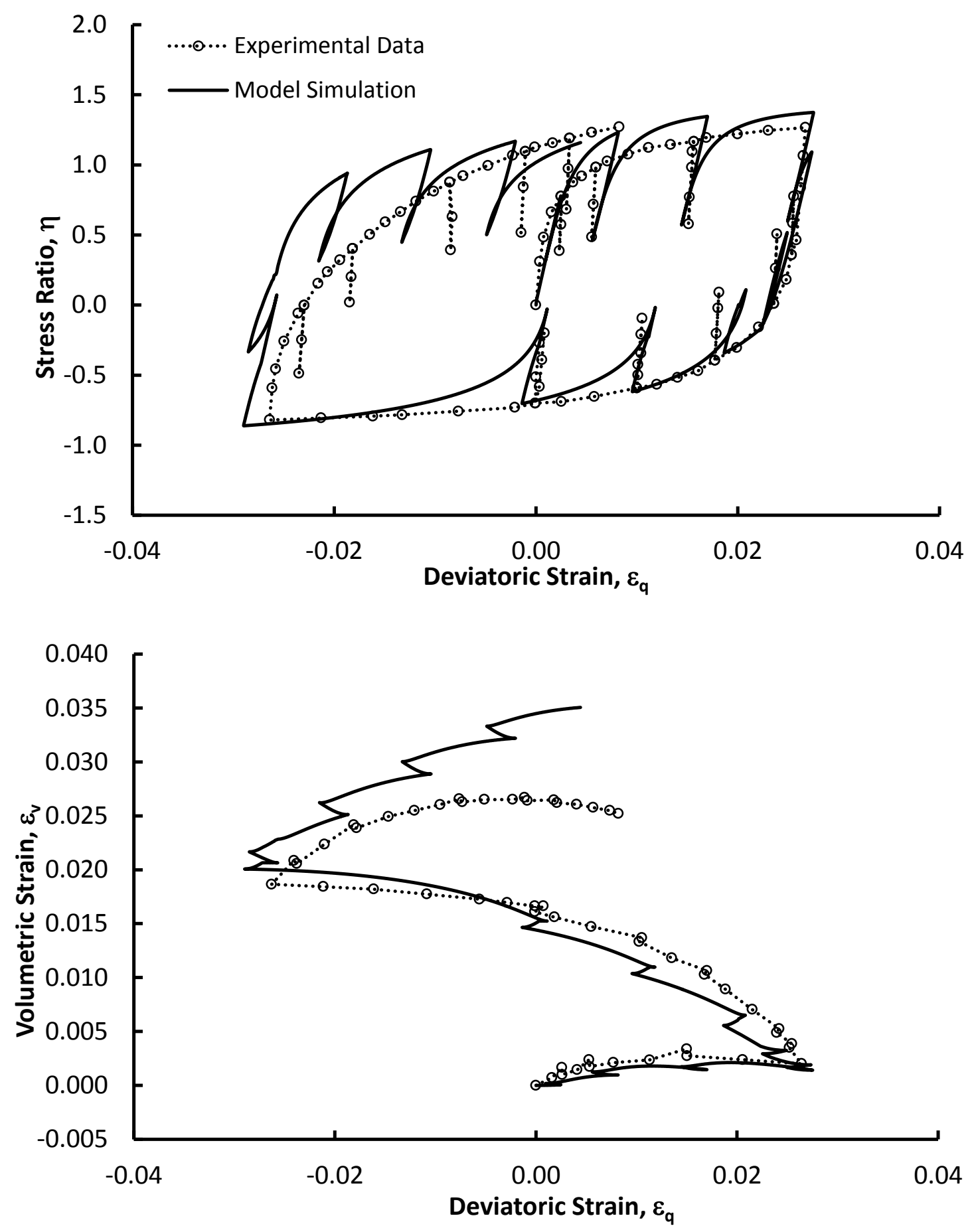

(b)

Figure 23: Drained cyclic test on a very loose sample of Toyoura sand with small hysteresis loops

(a) $\eta-\varepsilon_{q}$ plot and (b) $\varepsilon_{v}-\varepsilon_{q}$ plot 

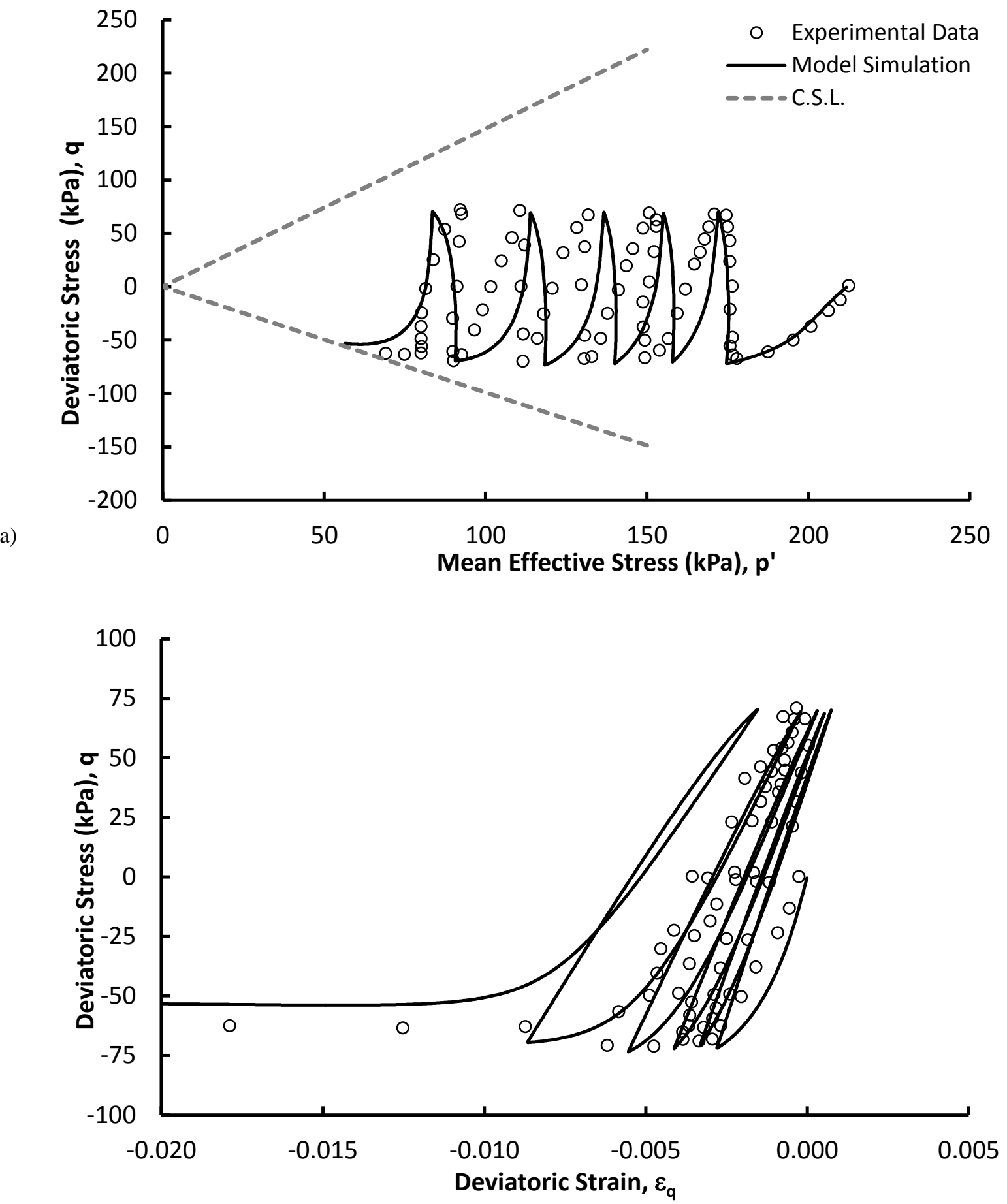

(b)

Figure 24: Undrained cyclic test with constant cyclic amplitude on a loose sample of Fuji River sand

(a) $q-p^{\prime}$ plot and (b) $q-\varepsilon_{q}$ plot 

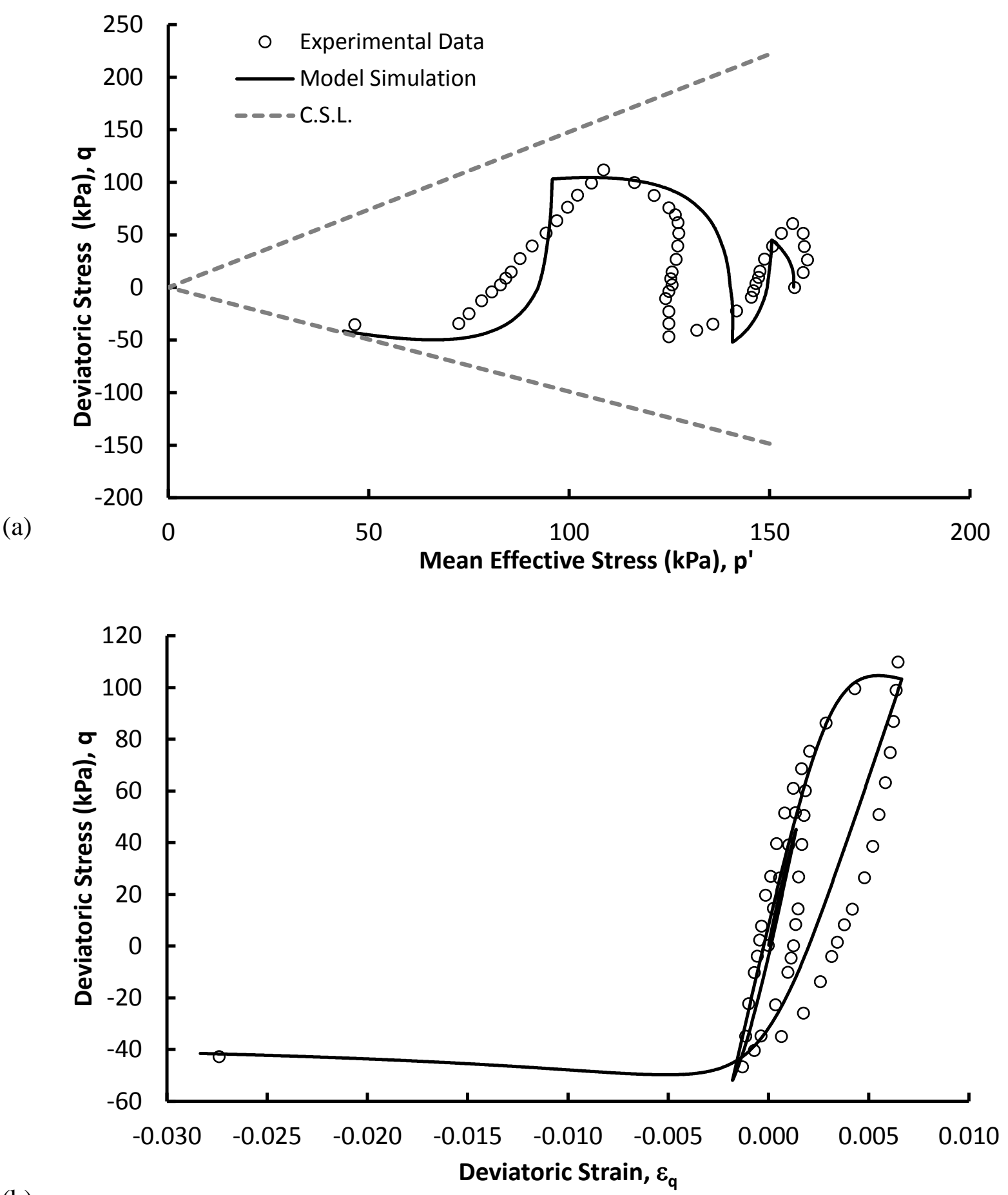

(b)

Figure 25: Undrained cyclic test with irregular cyclic amplitude on a loose sample of Fuji River sand

(a) $q-p^{\prime}$ plot and (b) $q-\varepsilon_{q}$ plot 
601 Figure 1: Critical State Line (CSL) and Limiting Isotropic Compression Line (LICL)

602 Figure 2: Effect of $\mathrm{N}$ and $\mathrm{R}$ on the shape of the bounding surface in $p^{\prime}-q-\theta$ space

603 Figure 3: Loading surface and mapping rule for first time loading

604 Figure 4: Loading surface and mapping rule for unloading/reloading

605 Figure 5: Vectors of plastic potential at $\boldsymbol{\sigma}^{\prime}$ for compressive and extensive loading

606 Figure 6: Drained cyclic test on a dense sample of Hostun sand

607 Figure 7: Drained cyclic test on a loose sample of Fuji River sand

608 Figure 8: Drained cyclic test on a loose sample of Toyoura sand

609 Figure 9: Stress paths in monotonic tests on Nevada Sand

610 Figure 10: Drained CIDC tests on loose samples of Nevada sand $\left(D_{r}=40 \%\right)$

611 Figure 11: Drained CIDC tests on dense samples of Nevada sand $\left(D_{r}=60 \%\right)$

612 Figure 12: Undrained CIUC tests on loose samples of Nevada sand ( $\left.D_{r}=40 \%\right)$

613 Figure 13: Undrained CIUC tests on dense samples of Nevada sand $\left(D_{r}=60 \%\right)$

614 Figure 14: Drained CADC tests with constant $p^{\prime}$ on Nevada sand

615 Figure 15: Drained CADC tests with constant $q$ on Nevada sand

616 Figure 16: Drained tests on Toyoura sand

617 Figure 17: Undrained tests on Toyoura sand

618 Figure 18: Stress paths used for tests on Toyoura sand (Pradhan et al., 1989a)

619 Figure 19: Drained tests with various stress paths on Toyoura sand 
620 Figure 20: Drained cyclic test on a loose sample of Toyoura sand

621 Figure 21: Drained cyclic test on a dense sample of Toyoura sand

622 Figure 22: Drained cyclic test on a very loose sample of Toyoura sand

623 Figure 23: Drained cyclic test on a very loose sample of Toyoura sand

624 Figure 24: Undrained cyclic test with constant cyclic amplitude

625 Figure 25: Undrained cyclic test with irregular cyclic amplitude

626 


\begin{tabular}{|c|c|c|c|c|c|c|c|c|c|c|c|c|}
\hline Soil & Reference & $\kappa$ & $v$ & $M_{c s}$ & $\lambda_{0}$ & $\lambda_{c r}$ & $(k P a)$ & $\Gamma_{0}$ & $N$ & $R$ & $k$ & $A$ \\
\hline Nevada Sand & $\begin{array}{l}\text { Arulmoli et al. } \\
\qquad \text { (1992) }\end{array}$ & 0.003 & 0.33 & 1.25 & 0.022 & 0.24 & 2000 & 1.910 & 1.5 & 3.0 & 2.0 & 1.5 \\
\hline Toyoura Sand & $\begin{array}{c}\text { Verdugo and } \\
\text { Ishihara (1996) } \\
\text { \& Pradhan et al. } \\
\text { (1989a\&b) }\end{array}$ & 0.008 & 0.3 & 1.24 & 0.033 & 0.24 & 2000 & 2.075 & 2.5 & 8.5 & 2.0 & 1.0 \\
\hline Fuji River Sand & $\begin{array}{l}\text { Ishihara et al. } \\
\text { (1975) }\end{array}$ & 0.01 & 0.3 & 1.48 & 0.032 & 0.21 & 1500 & 1.870 & 3.0 & 6.2 & 2.0 & 1.0 \\
\hline
\end{tabular}

628

629 


\begin{tabular}{cccccc}
\hline \multirow{2}{*}{ Soil } & \multicolumn{3}{c}{$k_{m 0}$} & & $\beta_{1}$ \\
\cline { 2 - 4 } & $\begin{array}{c}\text { First time } \\
\text { loading }\end{array}$ & $\begin{array}{c}\text { Unloading \& } \\
\text { reloading }\end{array}$ & & \\
\hline Nevada Sand & 6.2 & 115.8 & 0.95 & 0.34 \\
\hline Toyoura Sand & 1.2 & 76.0 & 1.05 & 0.3 \\
\hline Fuji River Sand & 2.0 & 18.0 & 0 & 0 \\
\hline
\end{tabular}

631

632 


\begin{tabular}{|c|c|c|c|c|c|}
\hline Soil Type & Test Type & $\begin{array}{c}\text { Sample/Load } \\
\text { Condition }\end{array}$ & ID & $v_{0}$ & $\begin{array}{c}p_{0}^{\prime} \\
(\mathrm{kPa})\end{array}$ \\
\hline \multirow{4}{*}{ Toyoura Sand } & \multirow{4}{*}{$\begin{array}{l}\text { Drained } \\
p^{\prime}=c s t\end{array}$} & Loose & 1 & 1.845 & \multirow{4}{*}{98.1} \\
\hline & & Dense & 2 & 1.653 & \\
\hline & & Very Loose & 3 & 1.865 & \\
\hline & & Very Loose & 4 & 1.855 & \\
\hline \multirow{2}{*}{ Fuji River Sand } & \multirow{2}{*}{$\begin{array}{l}\text { Undrained } \\
\text { cyclic }\end{array}$} & $\begin{array}{l}\text { Constant } \\
\text { Amplitude }\end{array}$ & 1 & 1.735 & 212.6 \\
\hline & & $\begin{array}{l}\text { Irregular } \\
\text { Amplitude }\end{array}$ & 2 & 1.749 & 156.0 \\
\hline
\end{tabular}

634

635

636 